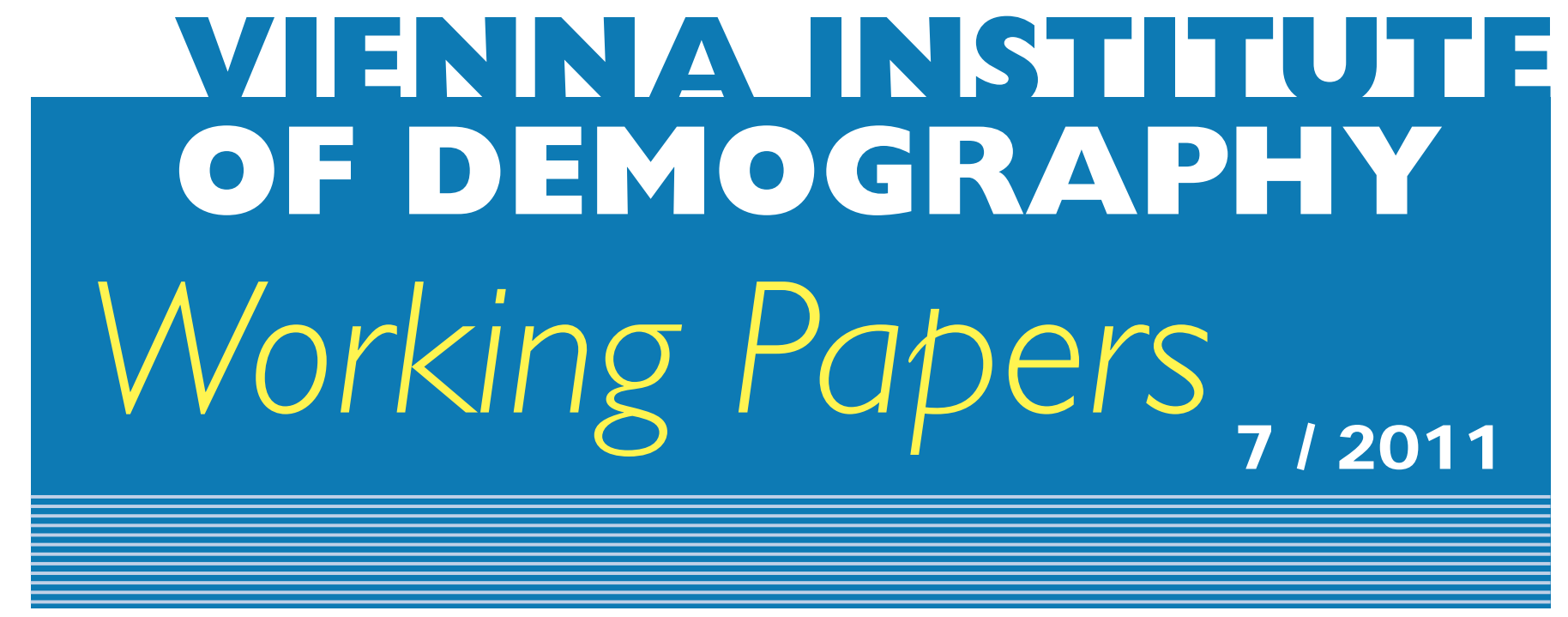

Kryštof Zeman, Tomáš Sobotka, Richard Gisser, M aria W inkler-D worak, and W olfgang Lutz

\title{
Geburtenbarometer Vienna: Analysing Fertility Convergence between Vienna and Austria
}

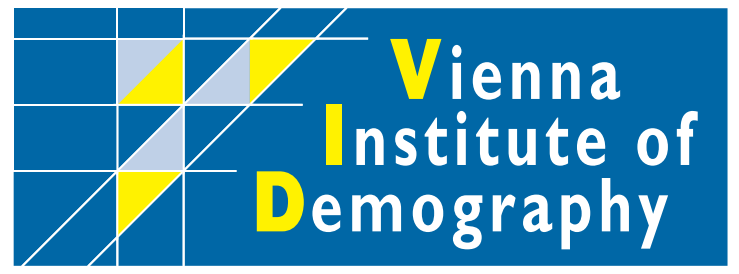

Vienna Institute of Demography Austrian Academy of Sciences

Wohllebengasse 12-14

A-1040 Vienna $\cdot$ Austria

E-Mail:vid@oeaw.ac.at

Website: www.oeaw.ac.at/vid

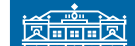

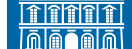

OAW

Austrian Academy of Sciences 


\begin{abstract}
Geburtenbarometer Vienna aims to provide an up-to-date monitoring of fertility in Vienna, based on a set of annual and quarterly indicators of fertility rates and regularly published summary reports. This paper gives an overview of the data, methods and indicators used and contrasts main results with the data for other Austrian regions and for the whole country. Throughout much of the 20th century, Vienna recorded fertility rates deep below those in other parts of Austria. Because fertility in Vienna differs markedly between Austrian-born and foreign-born women, our study looks at these fertility differentials and their influence on the overall fertility patterns for Vienna and Austria. Migrant women in Vienna not only had a rapidly increasing share on total births since the mid-1980s and thus contributed to a gradual increase in the absolute number of births in the city, but their higher fertility has also helped to push period fertility rates in Vienna towards the levels recorded in other regions of Austria. Our study brings to light the distinct population dynamics in Vienna, where high childlessness and low fertility are combined with a positive balance between births and deaths and sustained population growth and where the population trends are strongly influenced by the direct and indirect effects of migration.
\end{abstract}

\title{
Keywords
}

Fertility, Vienna, Austria, parity progression ratios, fertility measurement, migrants' fertility

\section{Authors}

Kryštof Zeman is research scientist at the Vienna Institute of Demography (VID), Austrian Academy of Sciences (ÖAW). Email: krystof.zeman@,oeaw.ac.at

Tomáš Sobotka is research scientist at the VID, ÖAW. Email: tomas.sobotka@,oeaw.ac.at

Richard Gisser is Deputy Director of the VID, ÖAW.

Maria Winkler-Dworak is research scientist at the VID, ÖAW.

Wolfgang Lutz is Director of the VID, ÖAW; Leader of the World Population Program, International Institute for Applied Systems Analysis, Laxenburg, Austria; Professor for Social and Economic Statistics, Vienna University of Economics and Business Administration; and Director of the Wittgenstein Centre for Demography and Global Human Capital.

\section{Acknowledgements}

We acknowledge the financial support obtained from the Culture Department of the city of Vienna that helped us to establish the Geburtenbarometer Vienna (grant number GZ: MA 7 2819/08). Some population data were gratefully supplied by the Unit for Statistics and Analyses of the City of Vienna (MA 5). The Geburtenbarometer project was supported by the Austrian Federal Ministry for Social Security, Generations and Consumer Protection grant number BMSG-442030/006-V7/2004. We are also thankful to Statistics Austria for the continuous provision of birth data and population statistics that help keeping the Geburtenbarometer up-to-date. 


\title{
Geburtenbarometer Vienna: Analysing Fertility Convergence between Vienna and Austria
}

\author{
Kryštof Zeman, Tomáš Sobotka, Richard Gisser, Maria Winkler-Dworak, and \\ Wolfgang Lutz
}

\section{Background}

In 2004 the Vienna Institute of Demography (VID) initiated the establishment of a fertility monitoring system for Austria, called Geburtenbarometer ("Birth Barometer", see Sobotka et al. 2005). Its main aim is to provide a continuous monitoring of period fertility trends using state-of-the-art methodology. This regularly updated monitoring allows an improved understanding of fertility developments which goes well beyond the use of annual indexes of fertility rates, especially the most widely used period Total Fertility Rate (TFR). Specifically, the Geburtenbarometer provides a series of age-, duration- and parity-specific indexes of fertility that show whether a change in the fertility trend over time can be attributed to changing first-birth rates or to changing progression rates to second- or higher-order births. These parity-specific fertility rates yield a summary index of total fertility, the Period Average Parity $(P A P)$, which is computed and published alongside the conventional Total Fertility Rates. PAP has two major advantages over the ordinary TFR. First, it is based on parity-specific indicators, and therefore it controls for the actual parity composition of the female population, which is not the case of the TFR that standardises fertility solely for the age distribution of women of reproductive age. Second, the $P A P$ is less affected by the ongoing changes in the timing of childbearing ('tempo effect'; Bongaarts and Feeney 1998) which have distorted the TFR in Austria since the 1970s. As a result, the PAP better reflects the actual fertility level (quantum) in Austria, and it also gets closer to the completed fertility rates of the birth cohorts of women having children during a given period of time. Finally, the Geburtenbarometer for Austria provides time series of fertility rates on a monthly basis, thus giving an opportunity to study the most recent shifts in fertility trends and to analyse fertility reactions to changing family policies and selected social and economic trends.

The successful launch of the Austrian Geburtenbarometer has also led to a wider spread of alternative fertility indicators that provide a welcome alternative to the period $T F R$, which has become increasingly perceived as a problematic and potentially misleading indicator of fertility (Sobotka and Lutz 2009). ${ }^{1}$ Right from the start, the idea of establishing a similar monitoring system in other countries and also in smaller regional units was considered. The grant provided by the City of Vienna within the framework of the advancement of science scheme (Wissenschaftsförderung) gives us an opportunity to establish the Geburtenbarometer for Vienna (Geburtenbarometer Vienna or, in German, Geburtenbarometer Wien) and gain unique insights into family building patterns and fertility trends in this city which used to have the lowest fertility rates in Austria until recently. We hope that the Geburtenbarometer Vienna will become a widely-used source of fertility data that will stimulate exciting analyses

\footnotetext{
${ }^{1}$ The Geburtenbarometer for Austria is maintained on the website of the Vienna Institute of Demography (see http://www.oeaw.ac.at/vid/barometer/).
} 
and motivate a further spread of the Geburtenbarometer. As in the case of Geburtenbarometer for Austria, birth monitoring for Vienna will provide both short-term (quarterly) and annual results in the form of brief reports and regularly updated databases accessible to all interested users.

\section{Introduction: Why Fertility Monitoring For Vienna?}

The Municipality of Vienna proudly sports a logo stating "Vienna is different" (Wien ist anders) on its advertising materials, booklets and posters. While this statement might not be true for all aspects of social life, it is well-fitting demographically, especially with respect to the capital's population composition, migration and fertility rates. When compared with the rest of Austria, Vienna, with a population of 1.69 million (2009), is a region of particularly strong immigration from abroad. According to the latest population census of 2001, 31 percent of the Viennese population were born abroad, far above the corresponding proportion for all of Austria (14 percent). Vienna also has a very distinct fertility pattern, which is, however, changing over time. In the past, similar to other large cities of Europe, fertility rates in Vienna were well below those recorded in other regions of Austria. At the peak of the economic recession of the 1930s, period TFR reached an extreme low level of 0.61 in 1934 (Gisser et al. 1975: 104, Table 39). During the post-war period, the Total Fertility Rate in Vienna remained below 2 and therefore well below the population replacement level ${ }^{2}$ even during the time of the baby boom that otherwise pushed the TFR in Austria to 2.82 in 1963. Because of persistently low fertility rates, Vienna until recently also showed a negative balance between births and deaths, which prevailed from the mid-1920s until 2004 (Statistics Austria 2009a). The prolonged period of low fertility rates resulted in an unusually rapid and early 'greying' of the population in Vienna, with the proportion of population above age 60 peaking at 28 percent already in 1970 (Lutz et al. 2003).

The data provided by the population census in 2001 show that low fertility in Vienna has largely been driven by high childlessness, which exceeded childlessness in the whole of Austria by 6-9 percent among women born in 1920-1960 (Figure 1, see also Prskawetz et al. 2008 and Spielauer 2005). More than a quarter of Viennese women born in 1960 remained permanently childless as compared to 16 percent among all women living in Austria. In addition, mothers in Vienna have fewer children on average: the mean number of children per mother has hovered around 1.9 for the cohorts born since 1940. In this indicator, a gradual convergence with the level for the whole of Austria can be observed for the cohorts born after 1935 , i.e. those having children since the 1950s.

\footnotetext{
${ }^{2}$ The 'population replacement' TFR is at around 2.08 at present, but it stood at around 2.2 in the 1950s (Council of Europe, 1990) due to higher infant and child mortality.
} 


\section{Figure 1}

Per cent of women remaining childless and the mean number of children per mother in Austria and Vienna, birth cohorts 1920-1960
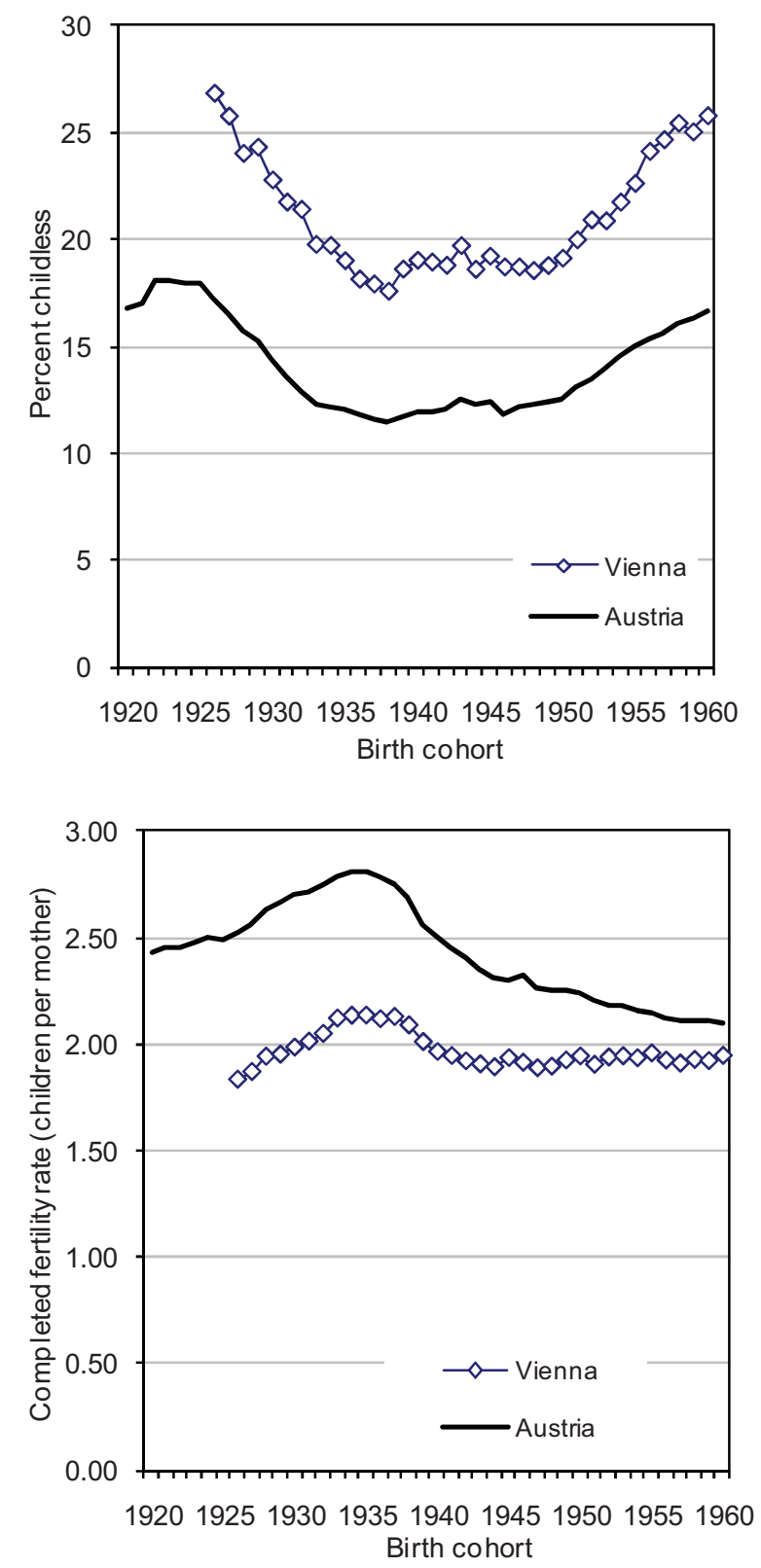

Source: 2001 Population Census (Statistics Austria 2005).

Several notable fertility and population trends can be observed for Vienna during the last 50 years. The gap in the period Total Fertility Rate between Austria and Vienna was closing over time: it first fell from 1.0 in 1961 to 0.3 in 1980 and completely disappeared by the early 2000s. Much of this convergence can be attributed to the fall in the TFR for Austria, while a small uptick in the TFR for Vienna around 2000 also helped to close this gap (Figure 2). In Vienna, the TFR was very low during the post-war period, estimated at 1.11 in 1951 (Gisser et al. 1975) and even the baby boom, peaking in 1963, did not take it above the 1.9 threshold. Subsequently, it reached another low of 1.24 already in 1977, much earlier than in the whole of Austria, where the lowest TFR of 1.33 was reached in 1995. 


\section{Figure 2}

Period Total Fertility Rate in Austria (1951-2009) and in Vienna (1951, 1961-2009)

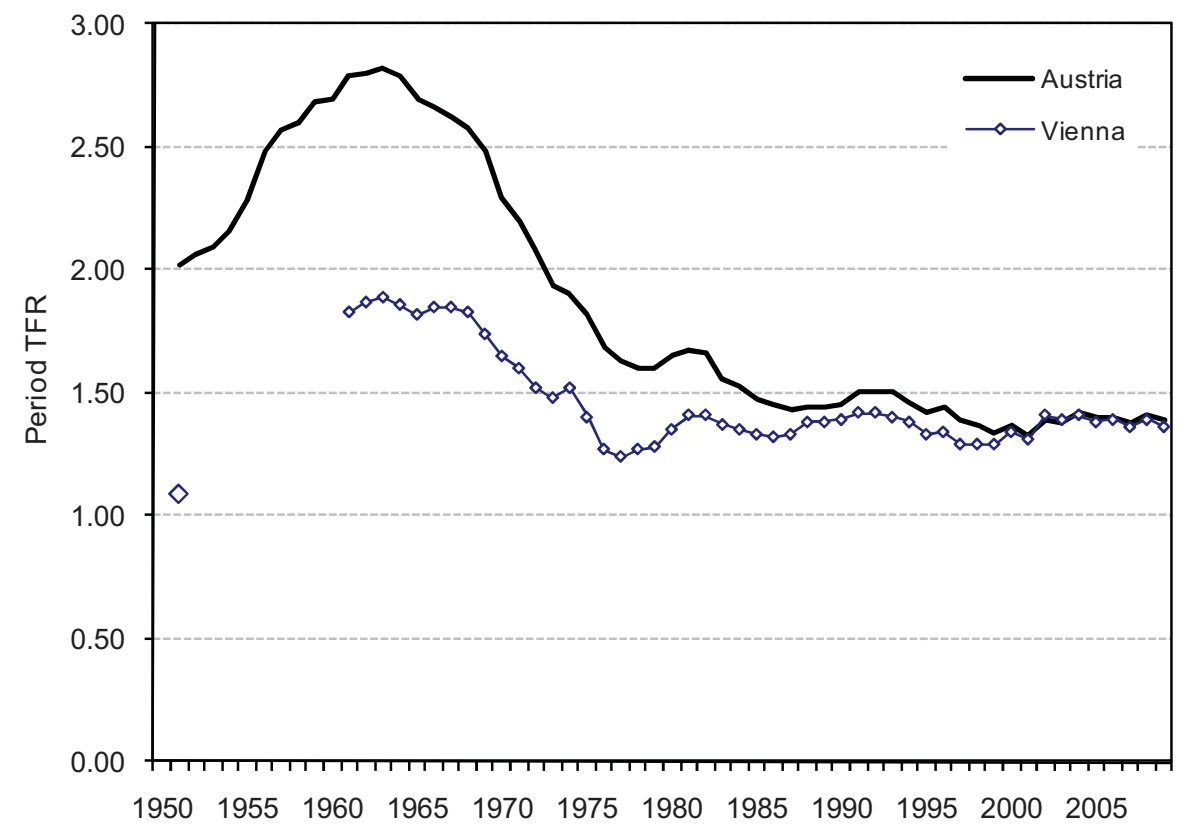

Sources: VID (2010), Eurostat (2009) and Statistics Austria (2009a) for Austria; Statistics Austria (2009b) and Gisser et al. (1975: 104, Table 39) for Vienna.

Another notable reversal took place in the natural population balance. For many decades, the number of deaths had outnumbered live births in Vienna by a wide margin and the contrast with the whole of Austria had been pronounced (Figure 3a). This natural population decline bottomed out in the mid-1970s: in 1976, the number of registered deaths in Vienna (26.7 thousand) was twice as high as the number of live births (13.4 thousand). Without migration, the Viennese population would shrink rapidly and in fact it was shrinking by almost 1 per cent per year between the mid-1970s and mid-1980s. Starting in the late 1970s, the initially high rate of natural population decline in Vienna had gradually diminished and after 2000 it turned into a positive balance between births and deaths. After 2005, the rate of natural increase in Vienna surpassed the natural increase for the whole of Austria for the first time since the early 20th century. This remarkable reversal, alongside with a renewed population growth since the late 1980s took place as a result of a combination of increasing longevity, rising immigration of the population of reproductive age from abroad and a slight increase in fertility rates. While the first factor was largely responsible for a continuous reduction in the number of deaths in Vienna by a staggering 43 percent between 1971 and 2009, the latter two factors jointly helped to push the number of births upward by one-third between 1977 and 2009 (Figure 3b). At the same time, high immigration also increasingly affected fertility patterns and fertility trends in Vienna (see Section 8). 
Figure 3a

Natural population increase (per thousand population) in Austria and Vienna (1960-2009);

Figure 3b

Number of live births and deaths in Vienna, 1961-2009
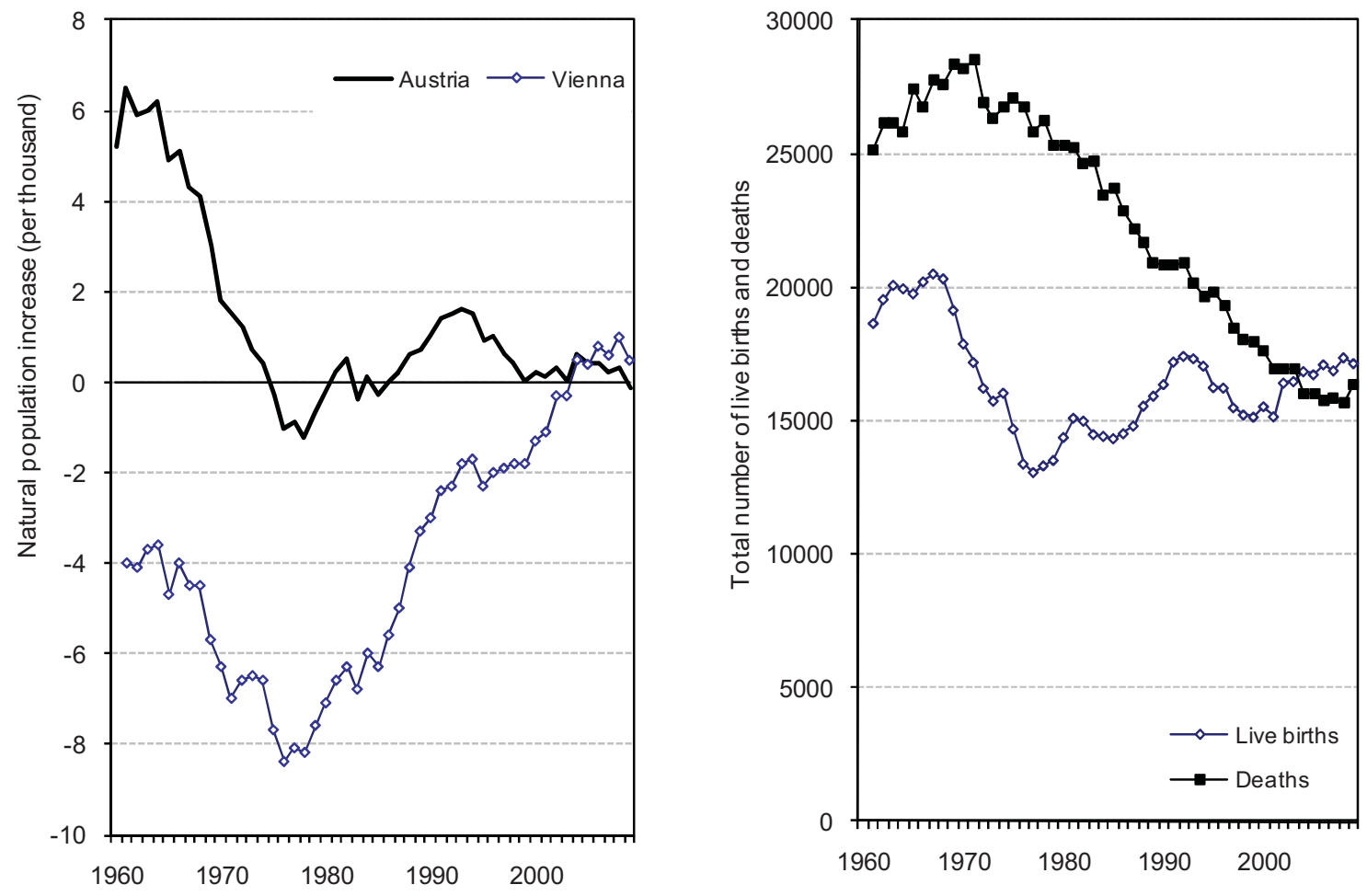

Source: Statistics Austria (2010).

These differences in fertility and population development between Vienna and other federal provinces of Austria make the analysis and monitoring of fertility trends in Vienna particularly interesting. The data analysed in this study also allow investigating the role of foreign migration in shaping fertility trends. To highlight the special position of Vienna in Austrian population development, we frequently contrast the results for Vienna with the combined data for other federal provinces of Austria and with the entire country. The next section summarises the main goals of the Geburtenbarometer Vienna as well as the research questions that can be addressed with these new fertility data. Subsequently, we outline the data used and the methodology and indicators analysed in this report. Then we give a detailed overview of annual indicators of fertility, looking also at shifts in the age schedule of fertility and first births in particular and briefly analysing the role of tempo effects on period fertility indicators used in the Geburtenbarometer. Next we look at the trends in quarterly fertility rates in Vienna. In addition, we analyse the role of foreign-born women in influencing the observed fertility developments in Vienna since 1999. The concluding section summarises major findings with a broader view on population dynamics in Vienna.

\section{Main Goals and Issues}

In analogy to the Geburtenbarometer for Austria, Geburtenbarometer Vienna primarily aims to provide an up-to-date monitoring of fertility in Vienna, based on a set of annual and quarterly indicators of fertility rates and regularly published summary reports. Unlike the Austrian Geburtenbarometer that provides monthly series of fertility data, Geburtenbarometer Vienna features quarterly time series only, to reduce random fluctuations 
in birth numbers, which are stronger in smaller populations at sub-national level. Quarterly data are adjusted for seasonality (regular seasonal fluctuations in birth rates) and for the number of calendar days in each quarter. The reports for Vienna compare fertility developments with those in the whole country and thus underline important differences and diverging trends. ${ }^{3}$ The quarterly data format facilitates a comparison of social, economic and policy trends with fertility trends and allows addressing questions such as "Did the economic recession affect first-birth rates?" or "Did improvements in child care provision correlate with changes in fertility rates?"

Geburtenbarometer Vienna also aims to facilitate comparative research and analyses of fertility in Vienna which, with its diverse population and strong immigration, can be seen as an example of a prominent European city with peculiar fertility trends. Within this perspective, a number of interesting research questions arise:

- What are the reasons for the convergence in period fertility rates between Vienna and the whole of Austria?

- Has a similar convergence taken place in first-birth rates and in the progression rates to the second, third and higher-order births?

- Are childlessness rates in Vienna staying well above those for all of Austria?

- Has the rising number of foreign-born mothers contributed to the slight rise in period fertility in Vienna after 1977 and to its convergence with the rest of Austria?

- Are the differences in fertility rates between foreign-born and Austrian-born women in Vienna disappearing?

These questions can be addressed directly with our database assembled for the Geburtenbarometer Vienna and are discussed in this report. Future extensions of our analyses could also add further dimensions - especially education and religion - to the investigation of fertility trends and differences. ${ }^{4}$ Vienna has the highest-educated, religiously most diverse and also the most secular population in Austria and these factors have shaped Viennese fertility trends in the past and contributed to the persistent low fertility in Vienna over the last century.

\section{Data}

Our study requires detailed data on live births, specified by the region (federal province) of mother's residence, mother's age, the child's birth order, time elapsed since the previous birth (for mothers of second and subsequent births) and mother's country of birth. We distinguish solely between mothers born in Austria and outside Austria as more detailed data on country of birth of the mother have become available only since 2008. Data specified for all these dimensions have been available in Austria since 1984, which is also the starting year of some of the data series presented in Geburtenbarometer.

Statistics Austria supplied us with extracts from individual birth records in 1984-2010, which allowed us to construct any of the presented indicators of period fertility. We draw on data on all live-born children in Vienna and, in a wider comparative perspective, in Austria

\footnotetext{
${ }^{3}$ The first regular report on Geburtenbarometer Vienna covers the year 2009 and has been published jointly with the report for the whole country on

http://www.oeaw.ac.at/vid/download/Geburtenbarometer Ergebnis Jahr2009.pdf

${ }^{4}$ Fertility differentials by religion among Viennese population will be studied in detail in a project Past, present and future religious prospects in Vienna 1950 - 2050 led by Anne Goujon, which will be carried out by the Vienna Institute of Demography in 2011-2014.
} 
between January 1984 and September 2010, consisting of 433,000 records for Vienna and 2.2 million records for Austria. These datasets are also used to estimate the exposure population for the parity progression ratios, namely, the number of women by parity and the year when they reached a given parity.

Estimating the denominator (female population at risk) required combining different data sources. For the most common period fertility indicator used, the period Total Fertility Rate (TFR), we use the age distribution of women aged 12-55 by single years of age in 19842009 provided by Statistics Austria (ISIS database) and the Statistics and Analysis Division of the City of Vienna. For 2002-2009 we also obtained the age distribution of the female population in Vienna and Austria by country of birth (only Austria and "all other countries" are distinguished). For computing the index of fertility controlling for age and parity (PATFR) in 2002-2009, used in the analysis of first-birth trends, we use the 2001 Census data on age and parity distribution of women resident in Vienna and update them with our quarterly and annual estimates of age- and order-specific fertility rates in 2001-2010. Additional time series of the distribution of the female population by age and parity in 1991-2001 were estimated from the 1991 Census data. Finally, to compute the most recent quarterly data we estimate the number of women by age in Vienna at the beginning of each quarter in 2010 from the published data for January 1 of 2010 and the age-specific relative quarterly population change during the year 2009 .

\section{Methods and Indicators}

The methodology used in Geburtenbarometer Vienna is mostly identical to that established in 2005 for Geburtenbarometer for Austria and described in detail in the article by Sobotka et al. (2005), especially in its online appendices. ${ }^{5}$ Here we outline a few differences and specify each of the indicators used.

Computing fertility indicators for periods shorter than one calendar year requires performing corrections for seasonality and calendar adjustments (correcting for different number of days in a month or quarter and for the number of weekdays when birth numbers fluctuate by weekday). In the Geburtenbarometer for Austria the X-12-ARIMA method implemented in the software package Gretl (Cottrell 2004) is used for these adjustments (Sobotka et al. 2005) and seasonality correction is computed separately for births of birth order 1, 2 and 3+. The same procedure is used to adjust quarterly data for Vienna, with one simplification: the data are not adjusted for the number of weekdays in each quarter as this affects quarterly birth data to a very minor extent.

\section{Fertility Indicators Analysed in Geburtenbarometer Vienna}

Consistent with the Geburtenbarometer for Austria two main indicators of period total fertility are computed: the conventional period Total Fertility Rate (TFR) and the Period Average Parity $(P A P)$. As in conventional demographic analysis, all indicators are computed from live births data and disregard stillbirths.

\footnotetext{
${ }^{5}$ Available on http://www.oeaw.ac.at/vid/download/Sobotka_et_al_Appendices_031005.pdf 


\section{The total fertility rate (TFR)}

This indicator is computed as a sum of age-specific fertility rates, $f(x)$, computed for a given period $t$ (calendar year or quarter-year) for women of all reproductive ages (ages 12 to 55 are considered in the Geburtenbarometer Vienna):

$$
\operatorname{TFR}(t)=\sum_{x=12}^{55} f(x, t), \text { where } f(x, t)=B(x, t) / P^{F}(x, t) .
$$

Note that $B(x)$ represents the number of live births to women aged $x$ and $P^{F}(x)$ stands for the average number of women aged $x$ living in the population in a period $t$ and estimated as a simple average between the number of women at the beginning and at the end of a given year or quarter. The TFR has been computed for each calendar year since 1984, and also for each quarter-year, starting in the first quarter of 2002. Since 2002, the annual TFR series have been also computed separately for women born in Austria and for those born outside the country.

When quarterly data are computed, the TFR is further multiplied by 4 and by an index adjusting for seasonality and calendar effects.

\section{The fertility index for first births controlling for age and parity $\left(P A T F R_{1}\right)$}

This is an index of the first-birth rate which, in addition to the age dimension used in constructing the period $T F R$, also controls for the parity composition of the female population. In the Geburtenbarometer the $P A T F R_{1}$ is computed from age-specific probabilities $\left(q_{1}(x)\right)$ of giving birth to a first child at age $x$ during a given period $t$, specified for the childless women:

$$
q_{1}(x, t)=B_{1}(x, t) / P_{0}^{F}(x, T),
$$

where $P^{F}{ }_{0}(x, T)$ denotes the total number of childless women aged $x$ at the beginning of period $t{ }^{6}$ For quarterly computations, calendar and seasonal adjustment is performed for each single age separately and each age-specific first-birth probability $q_{1}(x, t)$ is multiplied by 4 . The total fertility index for first births $\left(P A T F R_{l}\right)$ is computed as follows:

$$
\operatorname{PATFR}_{1}(t)=1-\prod_{x=12}^{55}\left[1-q_{1}(x, t)\right]
$$

This procedure of computing the period PATFR follows the methodology and notations introduced by Rallu and Toulemon (1994). ${ }^{7}$ Age $x$ refers to the age reached during the calendar year, which is calculated as a difference between the year analysed and the year of birth of the woman (mother). As the 'starting' exposure population of childless women by age was estimated on the basis of the 2001 population census, quarterly and annual time series of the $P A T F R_{1}$ for Vienna were computed for the period since 2002. In addition, the annual series of the $P A T F R_{1}$ was also computed for the period 1991-2001, using the population exposure data based on the 1991 census.

\footnotetext{
${ }^{6}$ Women reaching ages 12 to 55 in a given calendar year were considered. A few births that occurred to women below age 12 or above age 55 were coded as births to women aged 12 and 55, respectively.

${ }^{7}$ An alternative method of computing the age-parity-specific index of fertility, the PATFR, from age-and parityspecific fertility rates, $m_{i}(x)$, is used in the recently established Human Fertility Database (www.humanfertility.org) and described in detail by Jasilioniene et al. (2010).
} 


\section{Parity progression ratios based on duration since the previous birth $\left(P_{P P R_{i, i+1}}\right)^{8}$}

In the parity progression ratios used in this project, the transition rate between different parities is a function of the time elapsed since the previous birth. In contrast with the PATFR index specified above, duration since the previous birth rather than age is seen as a main parameter of fertility behaviour among women having at least one child. A summary indicator combining fertility rates across all birth intervals considered gives the period parity progression ratio $\left(P P R_{i, i+1}\right)$, where the notation $i, i+1$ denotes a transition from parity $i$ to the next parity $i+1$. For instance, the progression rate from the second to the third birth is denoted as $P P R_{2,3}$.

The Geburtenbarometer employs parity progression ratios constructed from the set of birth probabilities specified by duration (in years) from the last previous birth. This approach requires an estimation of the distribution of the female population by parity and the year of previous birth for each period considered. ${ }^{9}$ Duration- and parity-specific birth probabilities are computed for birth orders 2 and higher. For a woman who reached her current parity status $(i)$ in the year $y=t-d$, the probability to give birth to another child during the year $t$ is computed as follows:

$$
q_{i+1, d}(t)=B_{i+1, d}(t) / P_{i, d}^{F}(t),
$$

where $P_{i, d}^{F}(t)$ is the number of women who gave birth of order $i$ in the year $y=t-d$ and still remain at parity $i$ at the beginning of the year $t$ and $B_{i+1, d}(t)$ is the number of births of order $i+1$ during the year $t$ to women who gave their previous birth of order $i$ in the year $t-d$. In these computations $d$ represents 'duration' of stay at a given parity $i$, estimated as $d=t-y(y$ is the year of giving the previous birth). We estimated exposure for all durations up to 25 years. The highest birth order considered constitutes an open-ended parity progression to the fifth or higher-order birth among women who gave birth to four or more children:

$$
q_{5+, d}(t)=B_{5+, d}(t) / P_{4+, d}^{F}(t)
$$

For quarterly data, calendar and seasonal adjustment is performed for each durationand parity-specific probability separately, and each probability is multiplied by 4 . The exposure population is estimated for the beginning of each quarter.

Parity progression ratios $(P P R)$ were computed for women at parities 1, 2 and 3, and the open-ended parity category $4+$ :

$$
P P R_{i, i+1}(t)=1-\prod_{d=0}^{25}\left[1-q_{i+1, d}(t)\right]
$$

\footnotetext{
${ }^{8}$ For a brief description of duration and parity-specific indicators see Rallu and Toulemon (1994); for more details about the methodology employed in the Geburtenbarometer for Austria see Appendixes 2 and 3 in Sobotka et al. (2005).

${ }^{9}$ Detailed time series of birth data for Austria start only in 1984. To estimate the number of mothers by parity and the year of giving their previous birth, we aimed to cover a sufficiently long 'exposure' period, in this case at least 15 years (1984-1998). As a result, we computed all the duration-parity birth probabilities and parity progression ratios only from 1999 onward and, for the initial years, estimated the exposure population of women at long durations since the previous birth, i.e. having children before 1984. Because very few women give birth to another child at intervals over 15 years, our estimates of exposure population at long duration had no influence on the computed parity progression ratios.
} 
For the highest birth order considered, the parity progression computation reflects the cumulative progression rate to fifth and higher-order birth among women having four or more children and the computation can be simplified as follows:

$$
\operatorname{PPR}_{4+, 5+}(t)=\sum_{d=0}^{25} q_{5+, d}(t)
$$

In these computations, multiple births are treated as births with different birth orders. The estimated population of women by parity and year of previous birth does not account for the influences of mortality and migration, of which the latter is particularly intensive in Vienna. Thus, the 'zero migration' assumption is problematic and the actual numbers of women by parity and duration since the previous birth are affected by migration and therefore different from our estimates. Having no data on the parity and birth interval distribution of migrant women, we decided to ignore this effect. Based on our previous research, we expect that the model employed will still provide stable results, which are likely to lead to a slight overestimation of the 'real' parity progression ratios in the order of a few percentage points. ${ }^{10}$ We plan to study this issue in the future.

\section{Period average parity (PAP)}

The period average parity $(P A P)$ is computed for each parity category $j>1$ by combining the $P A T F R$ index for parity 1 with the parity progression ratios for parities up to $j$ :

$$
P A P_{j}(t)=\operatorname{PATFR}_{l}(t) \prod_{i=1}^{j-1} P P R_{i, i+1}(t)=P A P_{j-1}(t) \cdot P P R_{j-1, j}(t)
$$

The highest parity-progression category (4+ to 5+) accounts for the progression from the fourth birth to the fifth and all subsequent births:

$$
P A P_{5+}(t)=P A T F R_{1}(t) \prod_{i=1}^{4+} P P R_{i, i+1}(t)=P A P_{4} \cdot P P R_{4+, 5+}(t)
$$

The overall index of period average parity is computed as follows:

$$
P A P(t)=\operatorname{PATFR}_{1}(t)+\sum_{\mathrm{j}=2}^{5+} P A P_{j}(t)
$$

The PAP is computed for the whole period for which both $P A T F R_{1}$ and $P P R_{i, i+1}$ have been derived, i.e. for 1999-2009.

To sum up, Table 1 lists the indicators computed for the Geburtenbarometer Vienna and the periods for which they are computed. The next section gives an overview of major results, comparing the indicators computed for the city of Vienna with the whole of Austria and/or with the other federal provinces of Austria combined.

\footnotetext{
${ }^{10}$ While the numerator (number of births) is complete in our computations, the denominator-number of women by current parity and the year of giving previous birth - is underestimated, resulting in higher values of derived indicators of fertility.
} 
Table 1

Indicators computed for the Geburtenbarometer Vienna

\begin{tabular}{|l|l|l|l|}
\hline & Annual data & Quarterly data & Notes \\
\hline TFR & $1984-2009$ & $2002-2010(\mathrm{Q} 3)$ & $\begin{array}{l}\text { TFR also computed by birth order }\left(T F R_{i}\right) \text {. In addition, } \\
\text { annual } T F R \text { series also computed separately for } \\
\text { Austrian-born and foreign-born women in 2002-2009. }\end{array}$ \\
\hline PATFR $_{l}$ & $1991-2009$ & $2002-2010(\mathrm{Q} 3)$ & $\begin{array}{l}\text { Series break in 2002 (new exposure population based on } \\
\text { the 2001 census). }\end{array}$ \\
\hline PPR & & 2002-2010 (Q3) & \\
\hline$P A P$ & $1999-2009$ & $2002-2010(\mathrm{Q} 3)$ & Series break in 2002 (new series of the $\left.P A T F R_{l}\right)$. \\
\hline
\end{tabular}

\section{Overview of Main Results: Annual Data}

This section focuses on annual results; selected results of the quarterly analysis are examined in the next section. We first inspect the trends in the period Total Fertility Rate. While in the mid-1990s the TFR in Vienna was by more than 10 percent lower than the TFR in the other Austrian regions combined and the absolute difference amounted to 0.2 in 1984, this difference was almost erased by the early 2000s. Much of this convergence took place between 1997 and 2002, when the TFR in Vienna rose from a low of 1.29 to 1.41 (Figure 4).

\section{Figure 4}

Period Total Fertility Rate in Vienna, in other regions in Austria and in the whole of Austria (1984-2009)

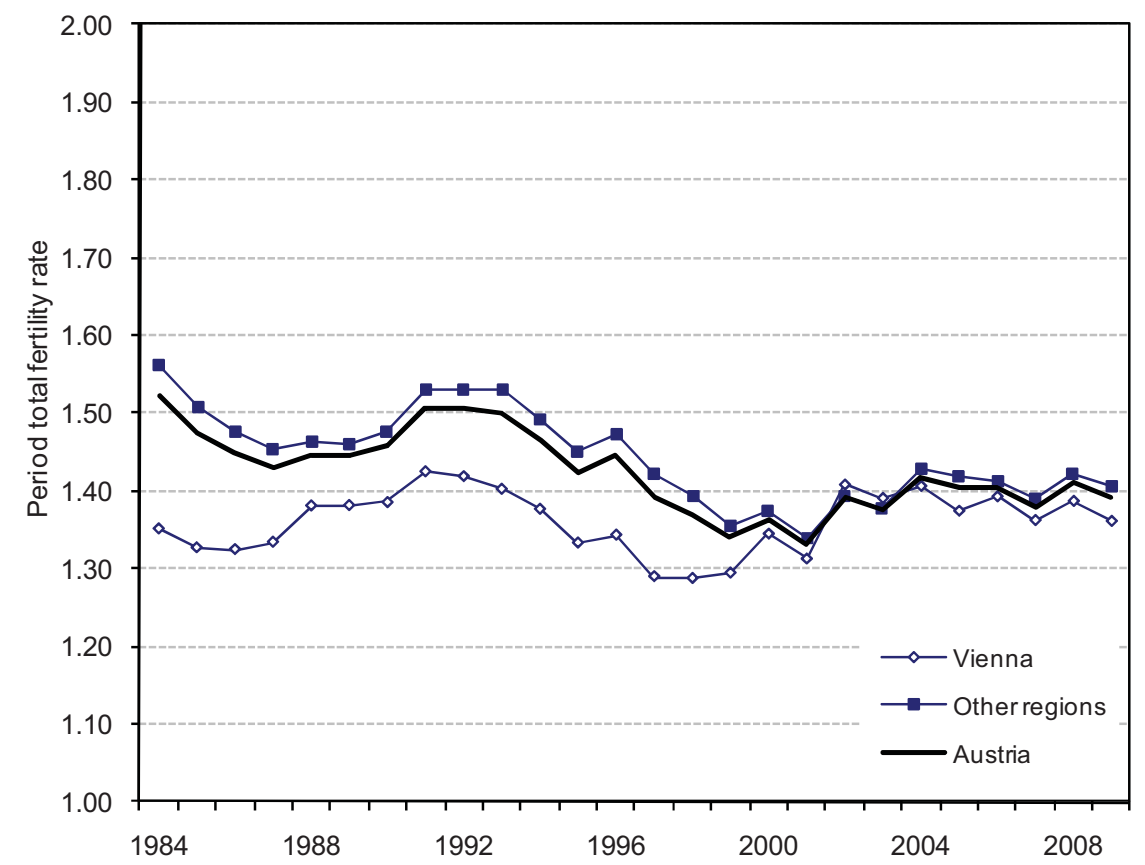

Source: Geburtenbarometer Vienna, authors' computations

When the period TFR is decomposed into its order-specific components, it becomes apparent that the main factor responsible for the convergence in the TFR between Vienna and 
other federal provinces of Austria is the convergence in the TFR for third and higher-order births. While the first-order $T F R\left(T F R_{l}\right)$ in Vienna has consistently surpassed that in other provinces since 1984 and the second-order $T F R_{2}$ consistently fell below the level in other provinces by a wide margin of 15-20 percent, the TFR for third and higher-order births $\left(T_{F R}{ }_{3+}\right)$ first stagnated and then briefly increased in Vienna-at a time when it was declining in other Austrian regions. The brief surge between 1999 and 2003 finally closed the 'gap', which amounted to 0.16 in absolute terms in 1984. Since 2003, the $T F R_{3+}$ in Vienna and in other Austrian regions combined has remained stable at around 0.25 (Figure 5).

\section{Figure 5}

Order-specific components of the period TFR in Vienna and in other federal provinces of Austria combined, 1984-2009
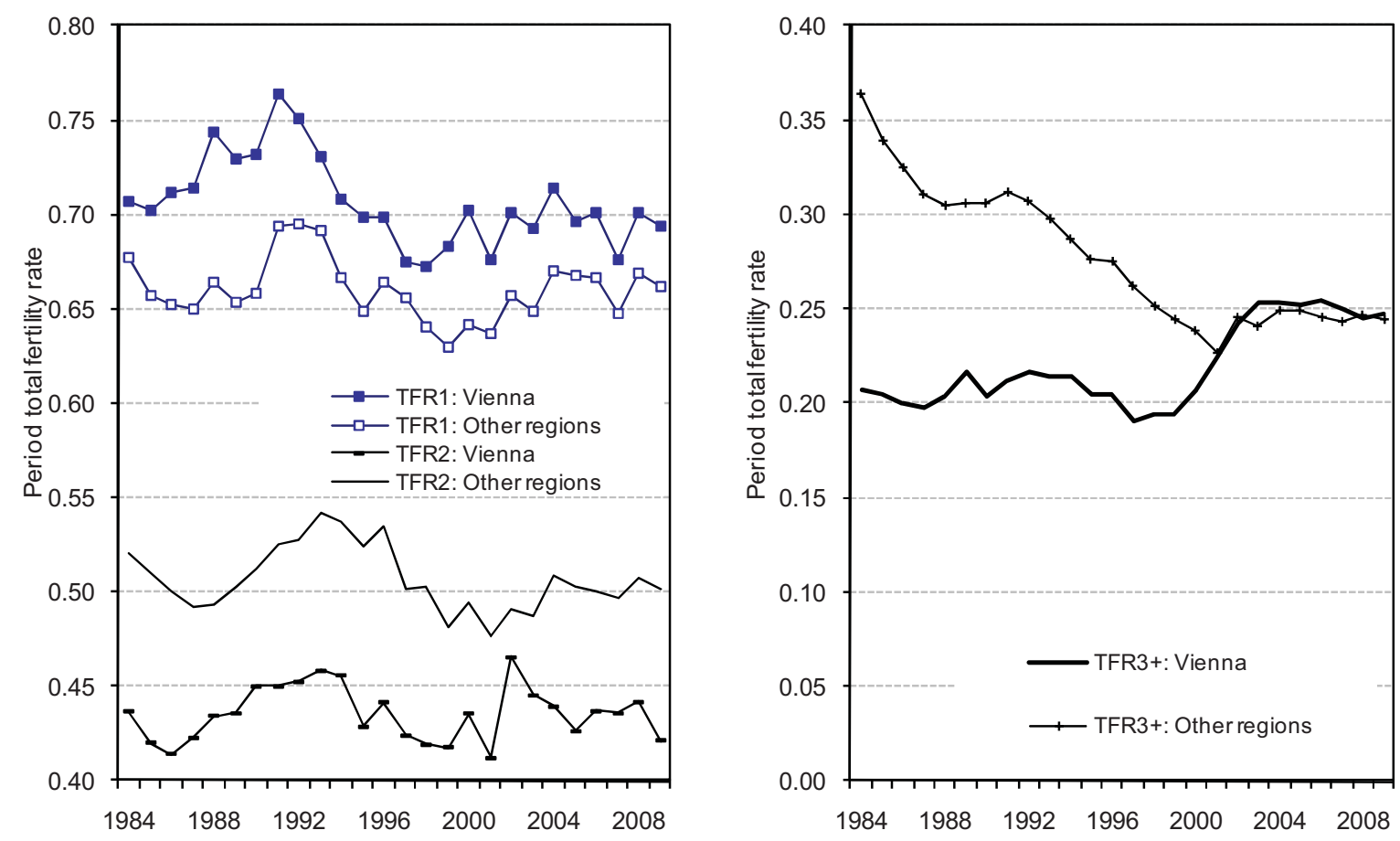

Source: Geburtenbarometer Vienna, authors' computations

However, the period TFR can give a distorted picture of fertility trends and levels because it does not take into account the actual parity distribution of the female population and it can be strongly affected by changes in the timing of childbearing. Therefore, we also inspect the trends in the Period Average Parity $(P A P)$ and its order-specific components to check whether the general convergence in fertility and particularly in higher-order birth rates can also be confirmed with these more appropriate period fertility indicators. Due to a shorter time series of the $P A P$ for Vienna, our analysis focuses only on the period between 1999 and 2009. Figure 6 shows that the $P A P$ in Vienna still remains slightly below the $P A P$ in other regions in Austria, although this difference has declined below 0.1 in absolute terms during the most recent period. The upswing in fertility in the late 1990s and early 2000s, indicated by the TFR, is also confirmed by the PAP, which rose from 1.40 to 1.52 between 1999 and 2004 . In 2009, the $P A P$ in Vienna stood at 1.49 as compared with the level of 1.57 for other regions of Austria combined and 1.54 for the whole country. In comparison, the period TFR was 1.36 for Vienna and at 1.39 for the whole of Austria. 


\section{Figure 6}

Period Average Parity $(P A P)$ in Vienna, in other regions of Austria and in the whole of Austria (1999-2009)

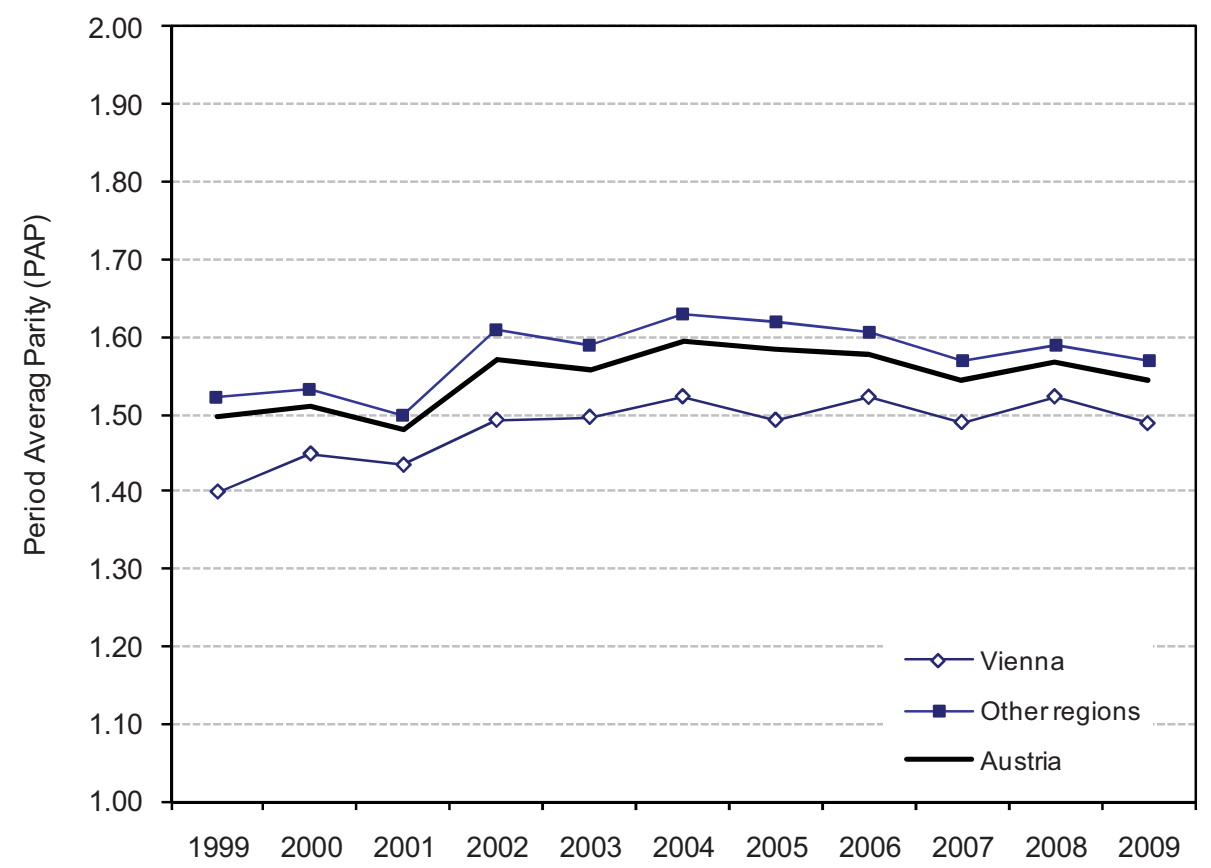

Source: Geburtenbarometer Vienna, authors' computations.

Note: Series break in 2002, following the change in the estimated distribution of women by age and parity after the 2001 population Census.

The parity-specific fertility indicators show that women in Vienna have slightly lower first-birth rates than women in the other Austrian regions. In 2000-2009, the first-birth fertility index, $\mathrm{PATFR}_{1}$ reached on average 0.72 in Vienna and 0.75 in Austria, implying a period childlessness rate of 28 percent in Vienna and 25 percent in Austria (Figure 7). ${ }^{11}$ This is broadly in agreement with the observed trends in cohort parity distribution, but in contrast with the period TFR for first births, where the value for Vienna consistently surpasses that for other Austrian regions combined (see above). However, since the period TFR is heavily affected by changes in fertility timing, we place more confidence in the parity-specific PATFR for first births. Parity progression ratios show, in line with the TFR indicators, that women in Vienna have a considerably lower progression rate to the second birth than women in other Austrian regions. In 2000-2009, the period PPRs suggest that three-quarters of Austrian women with one child who lived outside Vienna would have a second birth, whereas in Vienna, only two-thirds of women with one child would eventually give birth to a second one. In contrast, third and fourth parity progression rates in Vienna clearly surpass those in other regions of Austria since the early 2000s. In 2003-2009 the third birth progression rate was at 0.40 in Vienna and 0.35 in other regions; the difference was yet more pronounced for the fourth birth progression ratios. This result corroborates the finding on the sharp increase in the TFR for third and higher-order births in Vienna in the late 1990s reported above (Figure 5).

${ }^{11}$ Because the period PATFR for first birth is also negatively affected by tempo effects due to fertility postponement - although much less than the period TFR - it is likely that cohort childlessness will be lower. For women born in 1968, final childlessness is estimated in our computations at 28 percent for Vienna and at 19 percent for other regions of Austria. 


\section{Figure 7}

Parity-specific index of first births $\left(P A T F R_{1}\right)$ in 1991-2009 and parity progression ratios in 1999-2009 in Vienna and other Austrian regions combined
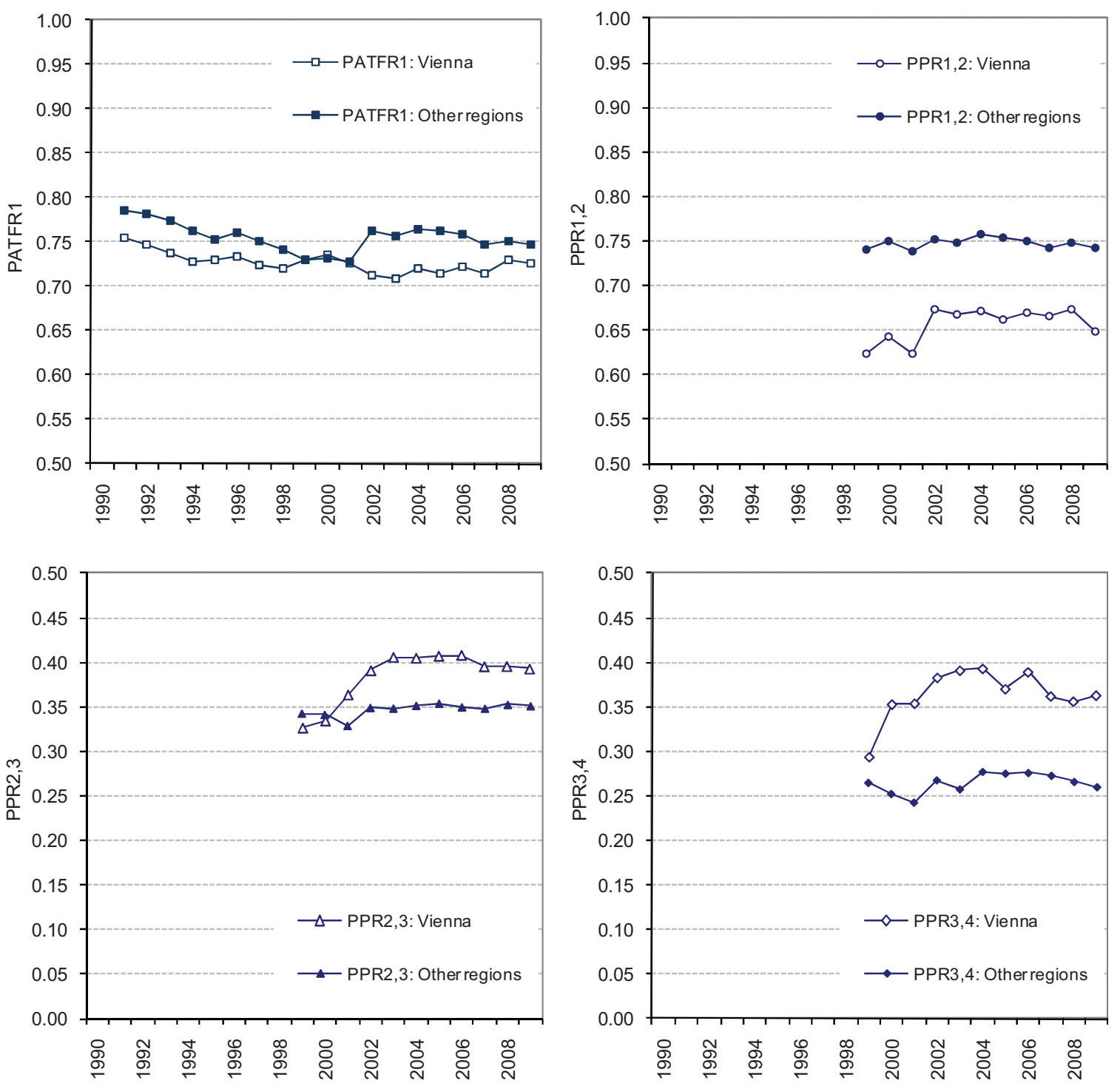

Source: Geburtenbarometer Vienna, authors' computations.

Note: Series break in 2002, following the change in the estimated distribution of women by age and parity after the 2001 population Census.

Women living in Vienna, owing to their higher-level education and better career opportunities, should be expected to have children later in life than women in other parts of Austria. This expectation is not confirmed for total births, where the trend in mean age at childbearing in Vienna and in other provinces has evolved in an almost identical fashion, with the mean age rising by three years between 1984 and 2009 and reaching 29.6-29.7 in 2009 (Figure 8). More in conformity to this hypothesis is the finding that women in Vienna used to bear their first child at a comparatively later age: in 1984 they had their first birth at age 25.0 on average, one year later than women in other regions (23.9). However, after 1984 the shift toward later first-birth timing was more pronounced outside Vienna, and around 2000, there was hardly any difference between Vienna and other regions left. In 2009 women in Vienna as well as in other provinces of Austria had their first birth at age 28 on average (Figure 8). 


\section{Figure 8}

Mean age at childbearing and at first birth in Vienna and other Austrian regions, 1984-2009
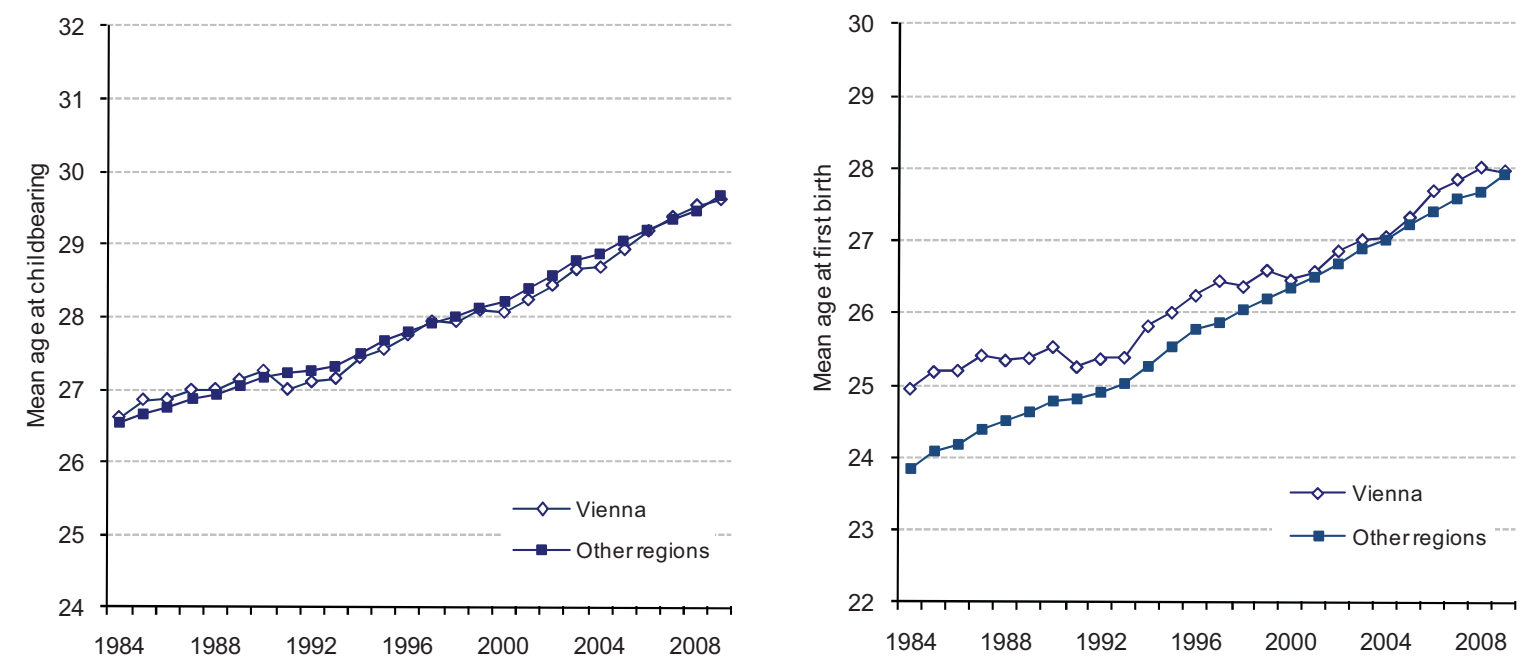

Source: Geburtenbarometer Vienna, authors' computations.

However, the trends in the mean age at childbearing conceal a considerable heterogeneity in the age pattern of fertility in Vienna. Figure 9 illustrates this heterogeneity using age-specific fertility rates and first-birth probabilities. In 1984, the schedule of agespecific fertility rates in Vienna almost followed the schedule for other regions of Austria combined, although at a lower level. By 2009, women in Vienna displayed elevated fertility rates at both lower (below 23) and higher reproductive ages (above 35) as well as a much less pronounced peak occurring at age 32. Even more pronounced are the contrasts in the age schedule of first-birth probabilities, which display a double-peaked curve in Vienna in 2009, with a sharp rise at very young ages and a local maximum at age 22 as well as a more pronounced peak at age 32. In contrast, the first-birth schedule in other regions is considerably more regular, with one peak at age 30 . 


\section{Figure 9a}

Age-specific fertility rates in Vienna and in other regions of Austria, 1984 and 2009
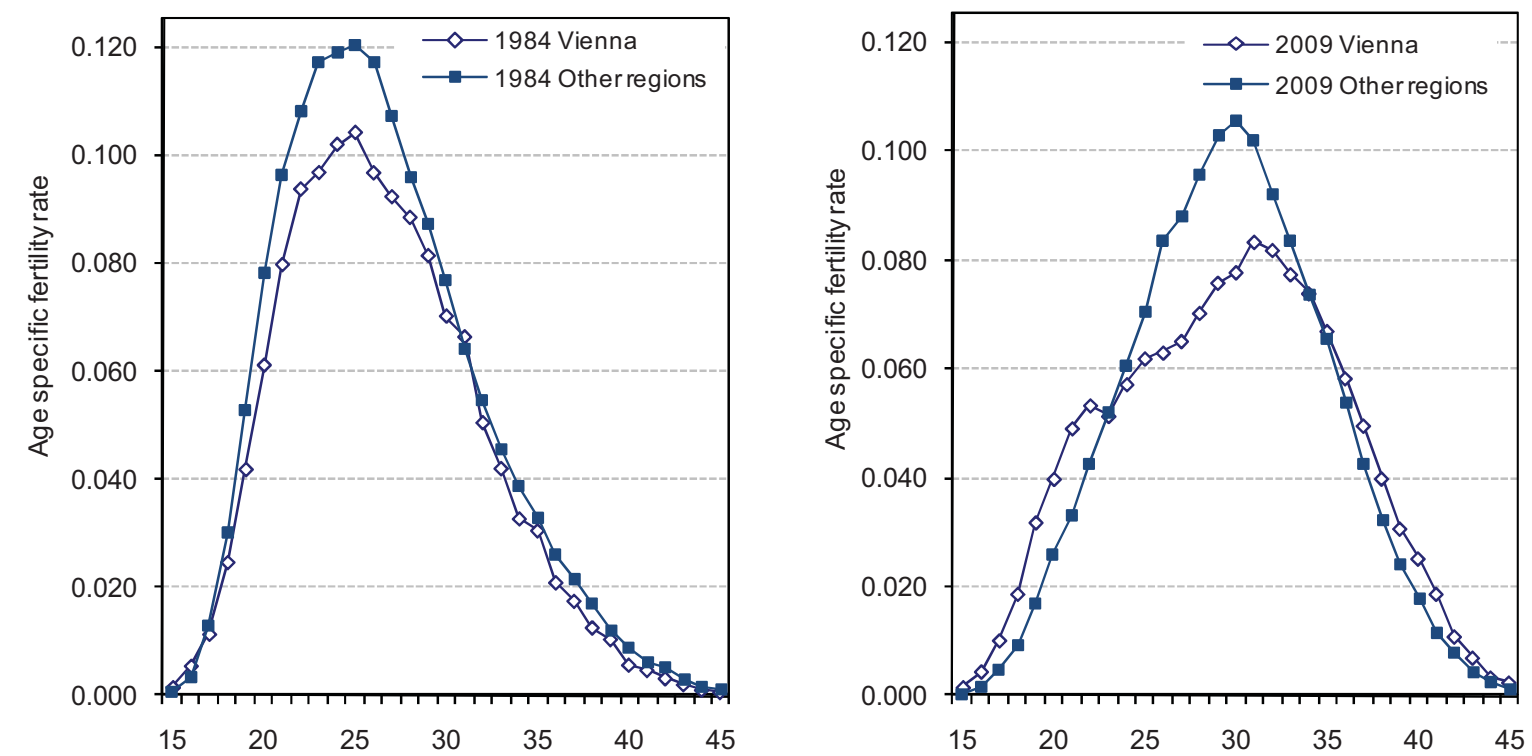

Figure 9b

Age-specific first-birth probabilities in Vienna and in other regions of Austria, 1991 and 2009
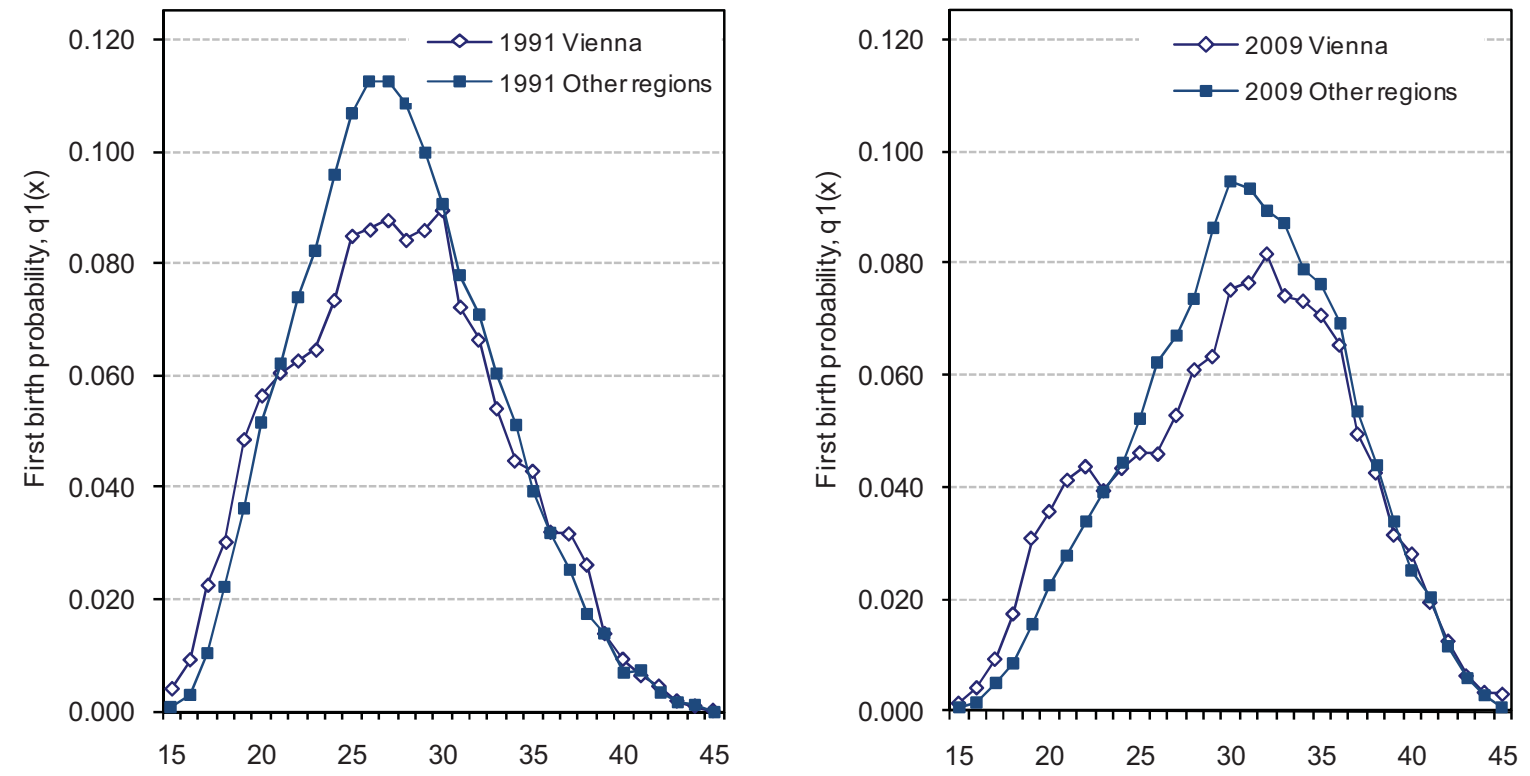

Source: Geburtenbarometer Vienna, authors' computations.

Note: Age reflects the age reached during the calendar year

To further illustrate the rising age differentiation in first-birth pattern in Vienna, Table 2 provides selected indicators of the timing of first birth in Vienna and other provinces of Austria in 1984 and 2009. In Vienna, the standard deviation of first-birth rates by age rose steeply between 1984 and 2009, reaching 6.2 years as compared with 5.3 years for other regions of Austria. In 2009, the share of first-birth rates above age 35 reached over 16 percent in Vienna as compared with 11 percent in other regions. Data on conditional first-birth probabilities show that the first-birth rate is considerably higher in Vienna than in other regions at both extremes of the reproductive span, with Viennese women below age 20 and 
above age 40 having a higher likelihood of first birth by 104 percent and 13 percent, respectively.

Table 2

Selected indicators of first-birth timing in Vienna and other regions of Austria, 1984-2009

\begin{tabular}{|c|c|c|c|c|c|c|c|c|}
\hline & \multirow[t]{2}{*}{ Mean age } & \multirow[t]{2}{*}{$\begin{array}{l}\text { Standard } \\
\text { deviation }\end{array}$} & \multicolumn{2}{|c|}{$\begin{array}{l}\text { Share of first birth } \\
\text { rates (in \%) }\end{array}$} & \multicolumn{4}{|c|}{$\begin{array}{c}\text { Conditional probability of having a first } \\
\text { birth }\end{array}$} \\
\hline & & & $\begin{array}{l}\text { Below } \\
\text { age } 25\end{array}$ & $\begin{array}{l}\text { At ages } \\
35+\end{array}$ & $\begin{array}{l}\text { Below } \\
\text { age } 20\end{array}$ & $\begin{array}{l}\text { Below } \\
\text { age } 25\end{array}$ & $\begin{array}{l}\text { At ages } \\
35+\end{array}$ & $\begin{array}{l}\text { At ages } \\
40+\end{array}$ \\
\hline \multicolumn{9}{|l|}{ Vienna } \\
\hline 1984 & 25.0 & 4.7 & 51.1 & 4.0 & $\ldots$ & $\ldots$ & $\ldots$ & $\ldots$ \\
\hline 1991 & 25.3 & 5.3 & 47.3 & 5.5 & 0.11 & 0.36 & 0.16 & 0.02 \\
\hline 2000 & 26.5 & 5.7 & 41.5 & 9.8 & 0.07 & 0.30 & 0.22 & 0.04 \\
\hline 2009 & 27.9 & 6.2 & 33.1 & 16.0 & 0.06 & 0.24 & 0.29 & 0.08 \\
\hline \multicolumn{9}{|l|}{$\begin{array}{c}\text { Other regions } \\
\text { of Austria }\end{array}$} \\
\hline 1984 & 23.9 & 4.3 & 61.5 & 2.1 & $\ldots$ & $\ldots$ & $\ldots$ & $\ldots$ \\
\hline 1991 & 24.8 & 4.5 & 51.2 & 3.1 & 0.07 & 0.36 & 0.14 & 0.02 \\
\hline 2000 & 26.3 & 4.9 & 37.8 & 5.7 & 0.04 & 0.25 & 0.18 & 0.03 \\
\hline 2009 & 27.9 & 5.2 & 27.2 & 11.1 & 0.03 & 0.18 & 0.30 & 0.07 \\
\hline \multicolumn{5}{|c|}{ Odds ratio Vienna vs. Other regions of Austria, 2009} & 2.04 & 1.31 & 0.98 & 1.13 \\
\hline
\end{tabular}

Source: Geburtenbarometer Vienna, authors' computations.

Notes: All indicators are based on age reached during the year; all women who will reach age $x$ during the year $t$ are therefore considered as being at age $x$ throughout the year, even if their actual age (age in completed years) at the time of giving birth was $x-1$. For instance, all women born in 1980 are counted as aged 29 during the whole year 2009. Due to lacking data on the parity distribution of the female population conditional first birth probabilities cannot be computed for the period prior to 1991 .

\section{Tempo effects in period fertility rates in Vienna and Austria}

Having analysed annual fertility trends in Vienna in detail, we now turn our attention to the role of tempo effects in period fertility indicators since 1990, using the adjusted period Total Fertility Rate (adjTFR) proposed by Bongaarts and Feeney (1998). This indicator gives a rough estimate of the magnitude to which the period TFR as well as the $P A P$ have been depressed by the ongoing shift towards later childbearing. Because the adjTFR for Vienna has been marked by huge fluctuations, Table 3 summarises results for two broader periods, 1990-99 and 2000-2006, over which these annual fluctuations are ironed out.

The $P A P$ can be used as a rough approximation of period fertility level undistorted by tempo effect that often strongly influences the period TFR (Sobotka et al. 2005). In 20002008, the PAP surpassed the period TFR by 0.11 in Vienna and 0.17 in Austria. Bongaarts and Feeney's (1998) tempo-adjusted TFRs suggests that the negative tempo distortion in the period TFR was actually higher, exceeding 0.25 for both Vienna and Austria. Table 3 indicates a convergence in fertility levels between Vienna and the whole of Austria in 20002008, with the TFR averaging at 1.4 and the adjTFR showing a considerably higher value of 1.64. Some difference remained in the $P A P$, which was by about 4 percent lower in Vienna. 
Table 3

Period TFR, PAP and tempo-adjusted TFR in Vienna and Austria, 1990-99 and 2000-2008

\begin{tabular}{|l|ccc|c|}
\hline & PAP & adjTFR & $\begin{array}{c}\text { Estimated tempo } \\
\text { effect } \\
\text { (TFR - adjTFR) }\end{array}$ \\
\hline Austria & TFR & PAP & & \\
1990-99 & 1.44 & & 1.64 & -0.20 \\
$2000-08$ & 1.39 & 1.55 & 1.64 & -0.26 \\
\hline Vienna & & & & \\
1990-99 & 1.36 & & 1.51 & -0.15 \\
2000-08 & 1.38 & 1.49 & 1.64 & -0.27 \\
\hline
\end{tabular}

Source: Geburtenbarometer Vienna, authors' computations.

\section{Main Results: Quarterly Data in 2002-2010}

The previous section has analysed fertility developments in Vienna using annual data. In this section we give a brief overview of the quarterly trends in the period TFR, PAP and in parity progression ratios in 2002-2010 ( $3^{\text {rd }}$ quarter). We focus on Vienna and do not provide a comparison with other Austrian regions as the results are almost identical to those discussed in the preceding section.

After performing adjustments for seasonality and calendar factors, quarterly indicators of fertility have been rather stable in Vienna during the analysed period. While some shortterm variations can be identified, especially for the Period Average Parity that has oscillated between 1.5 and 1.6, no clear longer-term trend can be observed once an upswing in fertility that started after 1999 came to an end in 2002. A similar stability in fertility trends after 2002 can also be observed in the time series of Austrian data (Sobotka et al. 2005, Prskawetz et al. 2008). The economic recession in 2008-2009 has not left a visible mark on the time trends in period fertility indicators for Vienna. A slight decline in most fertility indicators in the year 2009 has subsequently been compensated by a rise in the first three quarters of 2010 (Figure 10a).

Quarterly time series of the parity progression ratios depict minor fluctuations, especially for the third and the fourth birth progression ratios that are partly caused by the relatively low numbers of births observed at higher birth orders. Overall, the time series are remarkably stable, however, and especially the quarterly first- and second-birth progression ratios can easily be approximated by a straight line with very little variation over time. The recent recession has not had any visible effect on first-birth rates that stood at 0.72-0.74 in 2008 to 2010. At the same time, second-birth progression ratios showed a slight downturn, from 0.69 to 0.66 , between the first quarter of 2008 and the second quarter of 2009, followed by a rise in the first three quarters of 2010 up to the level of 0.71 (Figure 10b). Thus, the slight rise in period fertility in 2010 has been almost entirely accounted for by the upturn in second birth rates. ${ }^{12}$

\footnotetext{
${ }^{12}$ Arguably, a free provision of kindergartens in Vienna for children of all ages, effective since September 2009, might partly explain the subsequent rise in second birth rates. However, this possibility needs to be studied more rigorously and using a longer data series.
} 


\section{Figure 10a}

Quarterly series of the period Total Fertility Rate (TFR) and the Period Average Parity (PAP) in Vienna between 2002 and the third quarter of 2010

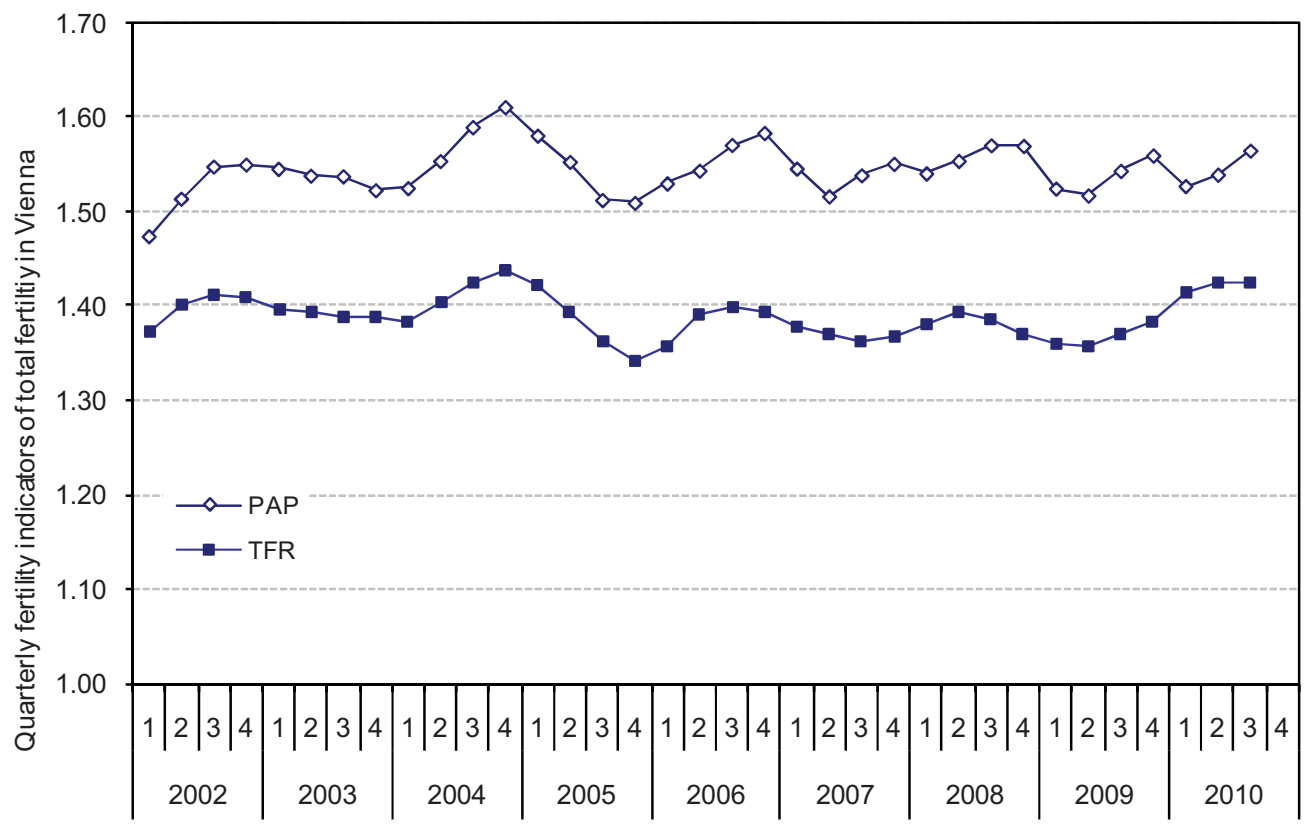

\section{Figure 10b}

Quarterly series of the period Parity Progression Ratios $\left(P P R_{i, i+1}\right)$ in Vienna between 2002 and the third quarter of 2010

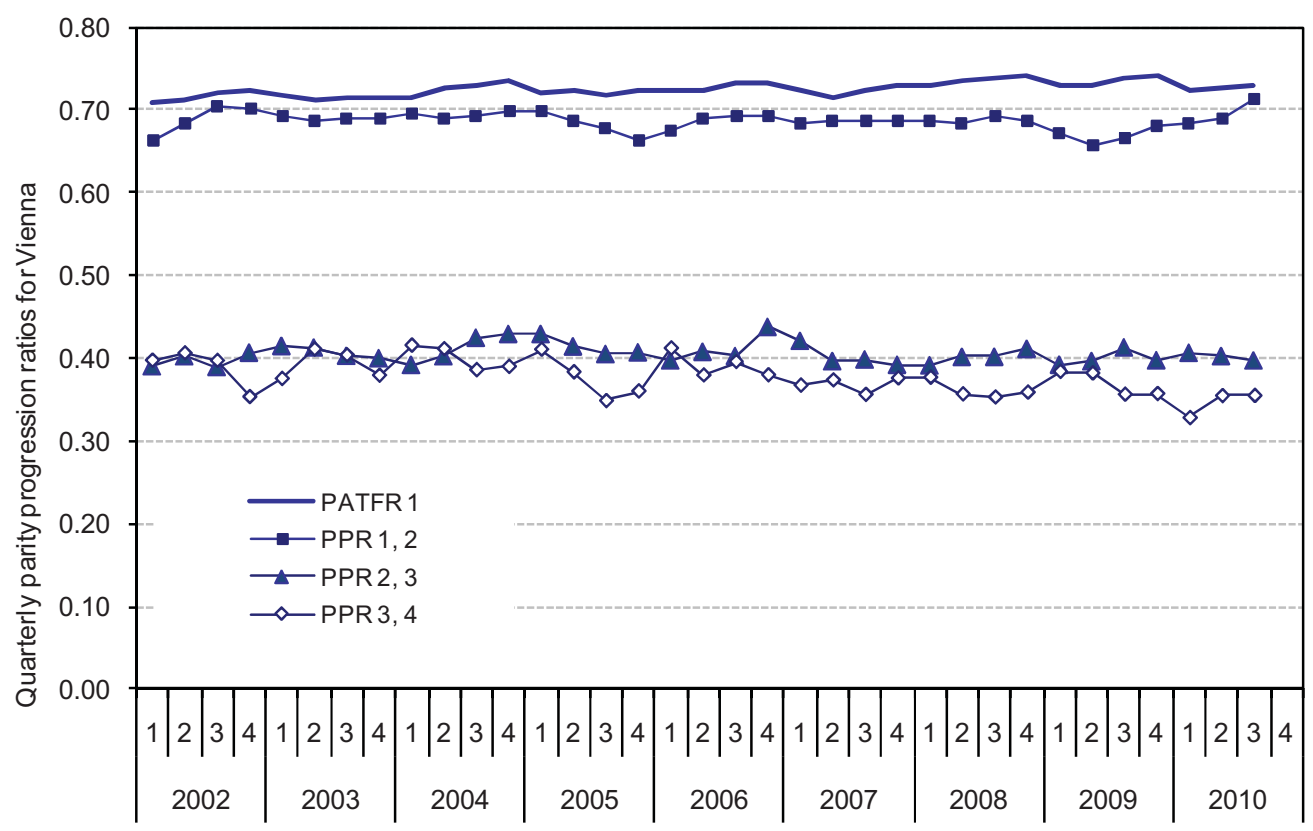

Source: Geburtenbarometer Vienna, authors' computations.

\section{The Rising Influence of Foreign-Born Women on Fertility Patterns in Vienna}

The findings on rising third- and fourth-birth progression rates and the increasing differentiation in the age patterns of childbearing in Vienna as well as on the convergence in 
fertility between Vienna and other regions of Austria suggest that foreign-born women, characterised by a distinct fertility behaviour, might have had an increasing influence on the observed fertility trends in Vienna. This section looks at the share of births to foreign-born mothers, analyses differential fertility by the country of origin and discusses the impact of foreign-born women on shaping fertility patterns in Vienna.

\section{Figure 11}

Percentage of births to foreign-born women in Vienna, in other provinces of Austria and in the whole of Austria, 1984-2009

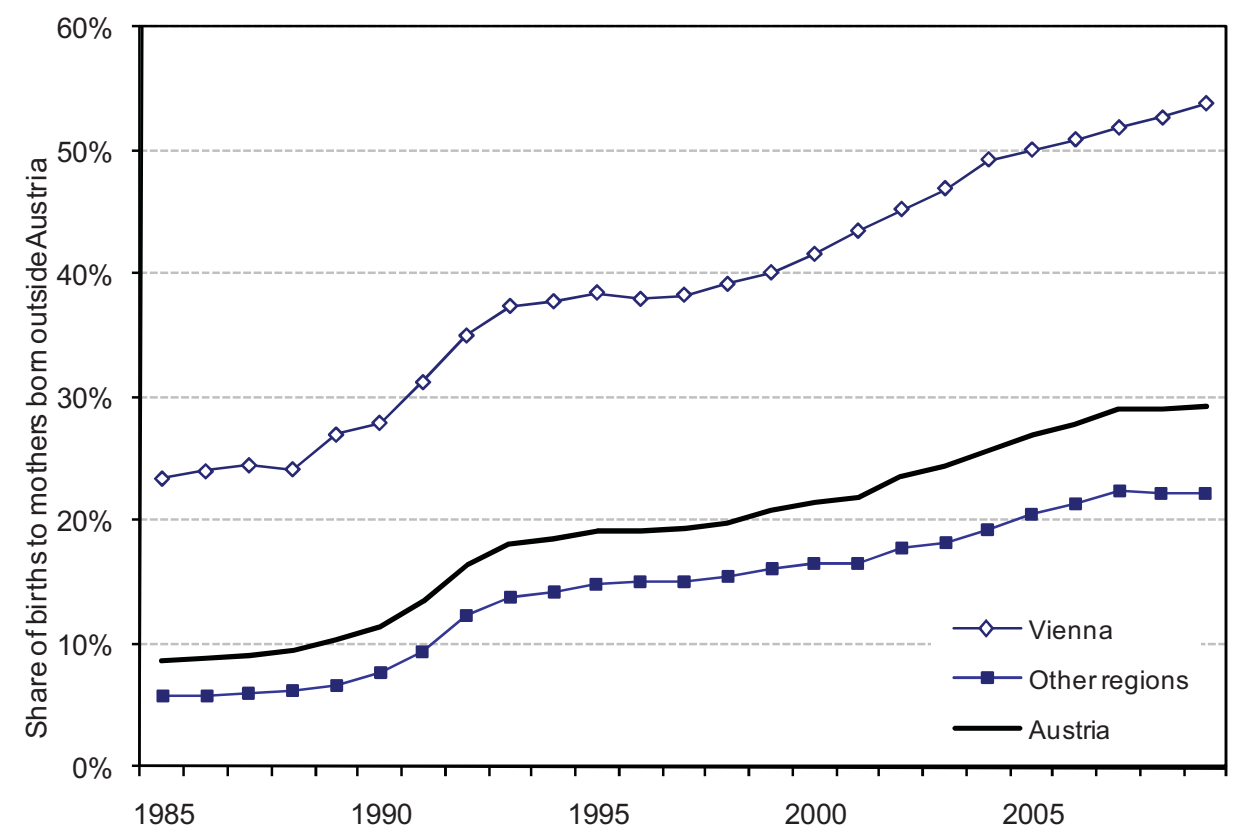

Source: Geburtenbarometer Vienna, authors' computations.

Figure 11 shows a remarkable increase in the proportion of births to foreign-born mothers in Vienna since the mid-1980s. Already in 1984, foreign-born women in Vienna accounted for 24 percent of all births, four times the value for other Austrian provinces. A continuous rise in the percentage of births to foreign-born women, briefly interrupted in the mid-1990s, pushed their share in Vienna above the 50 percent threshold in 2005. In 2009, foreign-born women accounted for a majority of 54 percent of live births in Vienna as compared with 22 percent in other Austrian provinces combined and 29 percent for the whole of Austria. This high share has been reached due to a combination of very low birth rates among Austrian-born women and high immigration rates to Vienna from abroad, leading to an increase in the number of foreign-born women of reproductive age. The higher fertility rate of foreign-born women is also reflected by their high share on third and higher-order births in Vienna: Whereas they accounted for less than one half (49 percent) of first births in 2009, their share reached 65 percent for third births and more than 70 percent for fourth and higherorder births (Appendix Table A7b).

Data available since 2008 allow us to analyse births by the mother's country of birth. Besides women born in Austria, who accounted for 46 percent of all births in Vienna in 2009, women from two other countries, Turkey and Serbia, also had a sizeable share of 10 percent and 6 percent, respectively, on total births (note that before the secession of Kosovo Serbianborn mothers accounted for a higher share of 8 percent of births in Vienna). In addition, women born in Bosnia and Herzegovina, Poland, Germany and Romania contributed by 
between 2 percent and 4 percent per country to total births, whereas women from all other countries accounted for one-fourth of total births in Vienna in 2009 (Appendix Table A6b).

The analysis of the period Total Fertility Rates in 2002-2009 specified by country of birth of the mother brings a number of important insights. ${ }^{13}$ First, the gap between the fertility of Austrian-born women and women born abroad is huge, especially in Vienna, where Austrian-born women recorded an extremely low TFR of 1.08 in 2009, whereas foreign-born women had a TFR of 1.82, i.e. by 68 percent higher (Figure 12; see also Table 4 below). This contrast is remarkable not for the higher fertility of foreign-born women, which is relatively low, but for the persistent extreme low fertility of Austrian-born women, whose fertility is by 0.2 lower in Vienna than in other regions of Austria. ${ }^{14}$ In contrast, the difference between the Total Fertility Rate of foreign-born women residing in Vienna and in other Austrian regions is much narrower.

Austrian-born women display a stable level of period fertility: In 2002-2009 their period TFR averaged 1.08 in Vienna and 1.32 in all other regions combined. This contrasts with a declining fertility among foreign-born women, particularly those living in Vienna, whose TFR fell from 2.05 to 1.82 during this period, thus narrowing their fertility differential with regard to Austrian-born women. However, these figures hide a huge heterogeneity in fertility of different groups of migrants, which has not been analysed yet for Austria (for other countries, see, e.g., Coleman 1994, Haug et al. 2002, Sobotka 2008, Garssen and Nicolaas 2008). When compared with the frequently published data specified by the nationality (citizenship) of mothers, the TFR of foreign-born women in Austria is considerably lower. In 2008, mothers with foreign nationality had a TFR of 2.01 (Kytir and Wisbauer 2009: 876, Table 8), whereas foreign-born women (including those with Austrian nationality) had a TFR of 1.90 (Table A5 in Appendix).

\footnotetext{
${ }^{13}$ Lacking data on parity distribution of women born outside Austria do not allow us to compute other fertility indicators than the period TFR. Therefore, this section does not analyse more sophisticated fertility indexes used in other parts of our report.

14 Such a low level of period fertility rate among Austrian-born women in Vienna might also be partly attributable to selective outmigration from Vienna to the surrounding suburban settlements among young Austrians who plan to have a larger family and acquire their own house or apartment in a presumably more family-friendly environment outside the city limits. Kulu (2006) shows that internal migrants to smaller settlements in Austria (towns and rural areas) have elevated fertility rates, while migrants to cities with population over 100,000 have very low fertility after migration.
} 


\section{Figure 12}

Period Total Fertility Rate among foreign-born and Austrian-born women living in Vienna and in the whole of Austria, 2002-2009

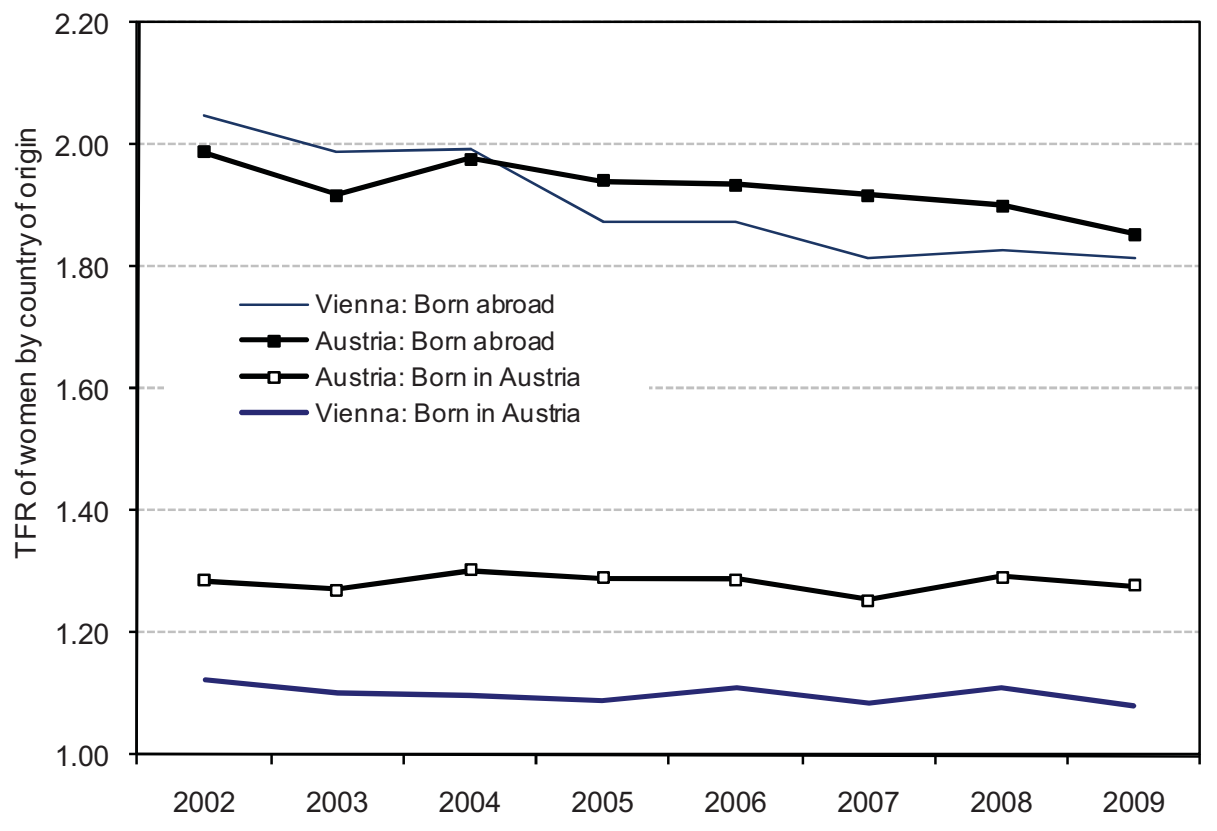

Source: Geburtenbarometer Vienna, authors' computations.

The most pronounced fertility contrasts between Austrian-born and foreign-born women in Vienna exist with respect to third- and higher-order fertility rates. Austrian-born women have a particularly low level of third- and higher-order $T F R$, which was stable at 0.14 in 2002-2009. In comparison, foreign-born women in Vienna had a three times higher $T F R_{3+}$, which nevertheless declined in this period, from 0.46 in 2002 to 0.39 in 2009 (Figure 13). These data suggest that the upturn in higher-order fertility rates in Vienna in the late 1990s can solely be attributable to the higher fertility of foreign-born women. However, we do not dispose of the data that would allow us to compute fertility by country of birth for the period before 2002 .

The absolute effect of foreign-born women on the period TFR can simply be estimated by computing a difference between the TFR for the whole country (region) and that of the native-born women, which represents a hypothetical TFR achieved in the absence of migration (e.g. Sobotka 2008). Table 4 shows that migrant women in Vienna have a substantial positive effect on the TFR which amounted to around 0.3 in absolute terms in 2002-2009. For the whole country, the net contribution of migrants was much lower, lifting the Austrian TFR level upward by 0.11 in 2009. 


\section{Figure 13}

Period Total Fertility Rate of birth order 3 and higher among Austrian-born and foreign-born women in Vienna, 2002-2009

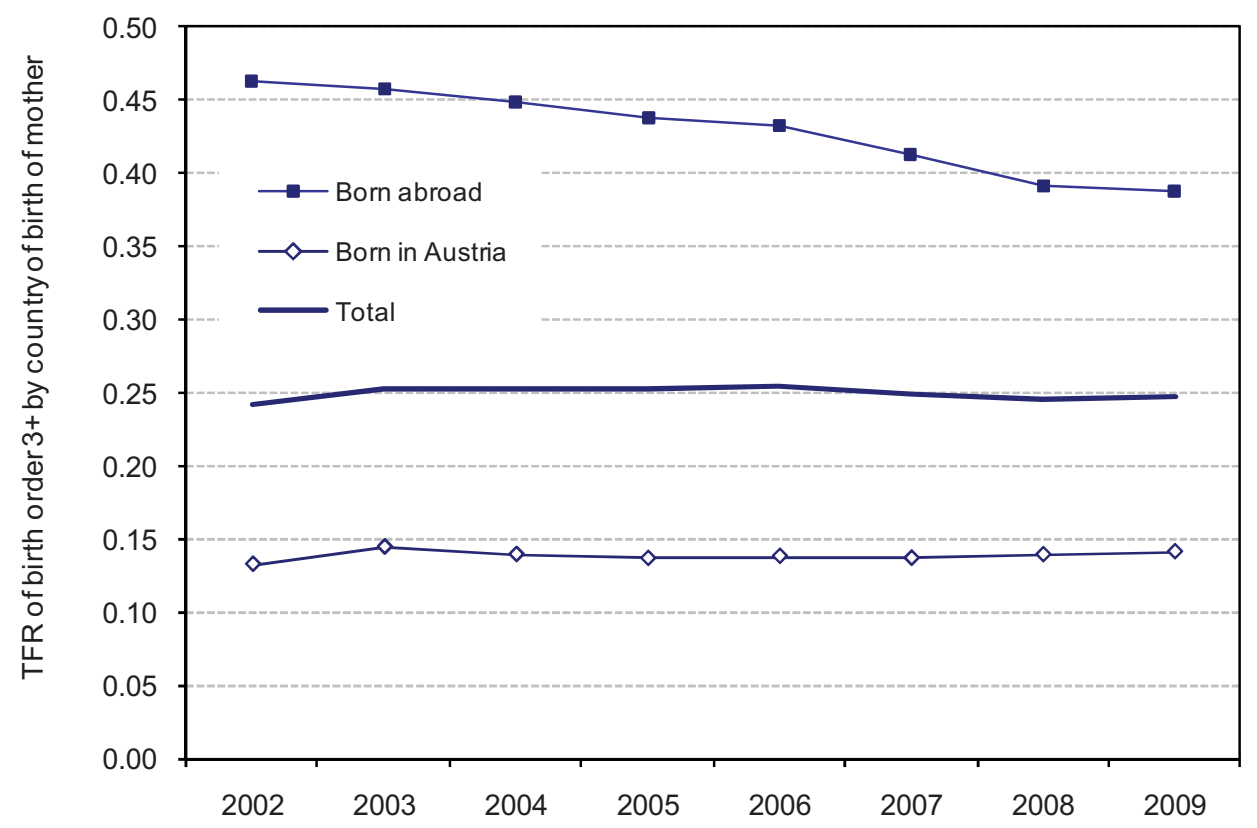

Source: Geburtenbarometer Vienna, authors' computations.

\section{Table 4}

Period Total Fertility Rate among Austrian-born and foreign-born women in Vienna and Austria and the net effect of migrant women on the period TFR, 2002-2009

\begin{tabular}{|c|c|c|c|c|c|}
\hline & $\begin{array}{l}\text { TFR, } \\
\text { Austrian- } \\
\text { born } \\
\text { women }\end{array}$ & $\begin{array}{l}\text { TFR, } \\
\text { Foreign- } \\
\text { born } \\
\text { women }\end{array}$ & Total TFR & $\begin{array}{l}\text { Abs. difference } \\
\text { Austrian vs. } \\
\text { foreign-born }\end{array}$ & $\begin{array}{l}\text { Net effect of } \\
\text { migrants' fertility } \\
\text { on total TFR }\end{array}$ \\
\hline \multicolumn{6}{|l|}{ Vienna } \\
\hline 2002 & 1.12 & 2.05 & 1.41 & 0.93 & 0.29 \\
\hline 2005 & 1.09 & 1.87 & 1.37 & 0.78 & 0.28 \\
\hline 2009 & 1.08 & 1.82 & 1.36 & 0.74 & 0.28 \\
\hline \multicolumn{6}{|l|}{ Austria } \\
\hline 2002 & 1.29 & 1.99 & 1.39 & 0.70 & 0.11 \\
\hline 2005 & 1.29 & 1.94 & 1.41 & 0.65 & 0.12 \\
\hline 2009 & 1.28 & 1.85 & 1.39 & 0.58 & 0.11 \\
\hline
\end{tabular}

Source: Geburtenbarometer Vienna, authors' computations.

Trends in childbearing tempo (timing) are also characterised by sizeable differences between Austrian-born and foreign-born women. Although both groups tend to have their first births at progressively later ages, foreign-born women show a less intensive delay of childbearing and become mothers earlier in life. In Vienna the difference in the mean age at first birth between these two groups of women approaches three years (Figure 14). In addition, Austrian-born women in Vienna have their first births about a year later than Austrian-born women in other regions. In 2009, the overall mean age of mothers at first birth in Vienna was 27.9 years, with the mean age for Austrian-born women surpassing age 29 and the mean age for foreign-born women reaching 'only' 26.4 years. 


\section{Figure 14}

Mean age at first birth among foreign-born and Austrian-born women living in Vienna and in the whole of Austria, 2002-2009

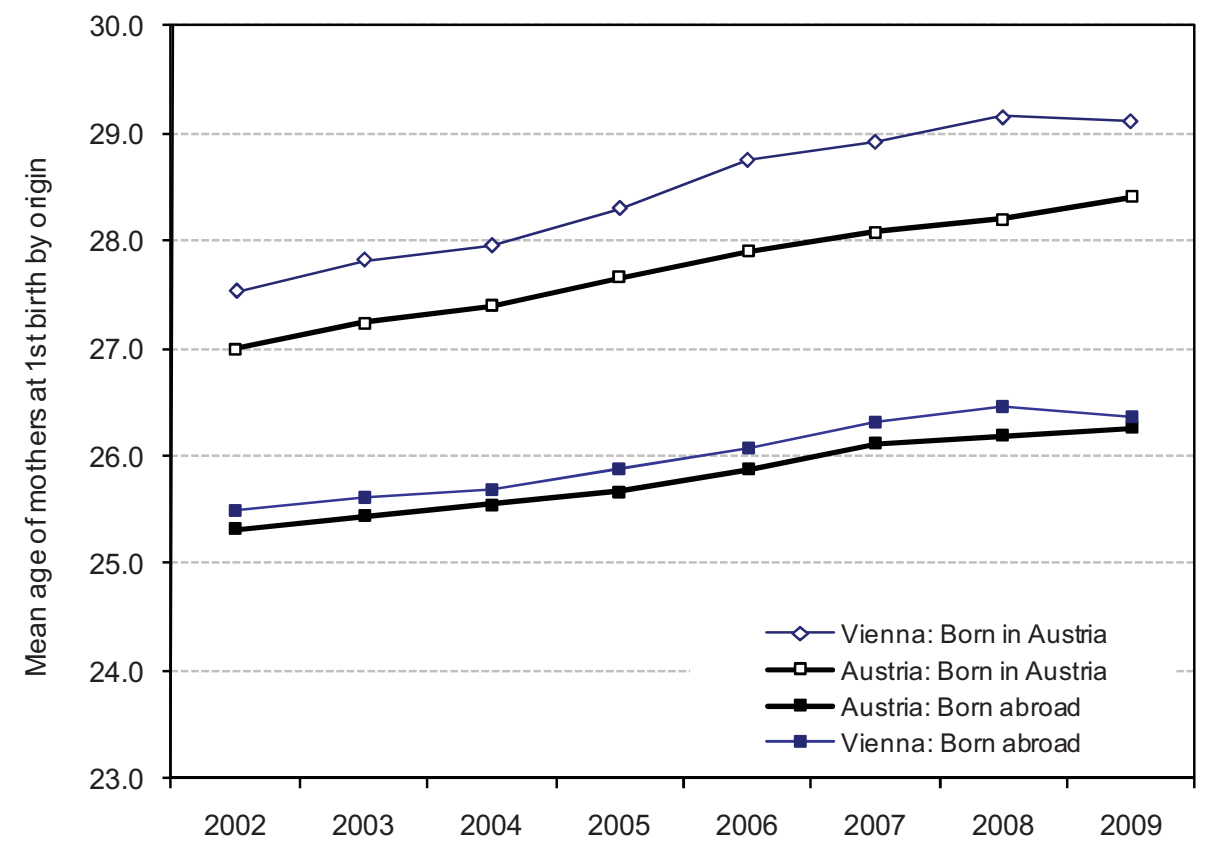

Source: Geburtenbarometer Vienna, authors' computations.

Different age patterns of childbearing in Vienna among Austrian-born and foreign-born women are further illustrated in Figure 15. Without the contribution of foreign-born women, the age schedule of fertility in Vienna would be considerably 'delayed' and would differ more markedly from the fertility schedule in other parts of Austria (see Figure 9a above). The fertility rates of foreign-born women surpass those among Austrian-born women in Vienna by a wide margin at all ages until 35 years and they are twice as high at ages 19-25. Even more marked differences are found in the age-specific schedule of first-birth rates, which peaks at a young age of 21 for foreign-born women and at late 32 years among Austrian-born women. The age schedule of first-birth rates in Vienna, which has no pronounced peak and two local maxima at ages 22 and 30, is thus a product of two distinct family-building patterns prevailing among Austrian-born and foreign-born women, respectively. 


\section{Figure 15}

Age-specific fertility rates (incidence rates), total (left-hand panel) and for first births (righthand panel), among Austrian-born and foreign-born women in Vienna, 2009
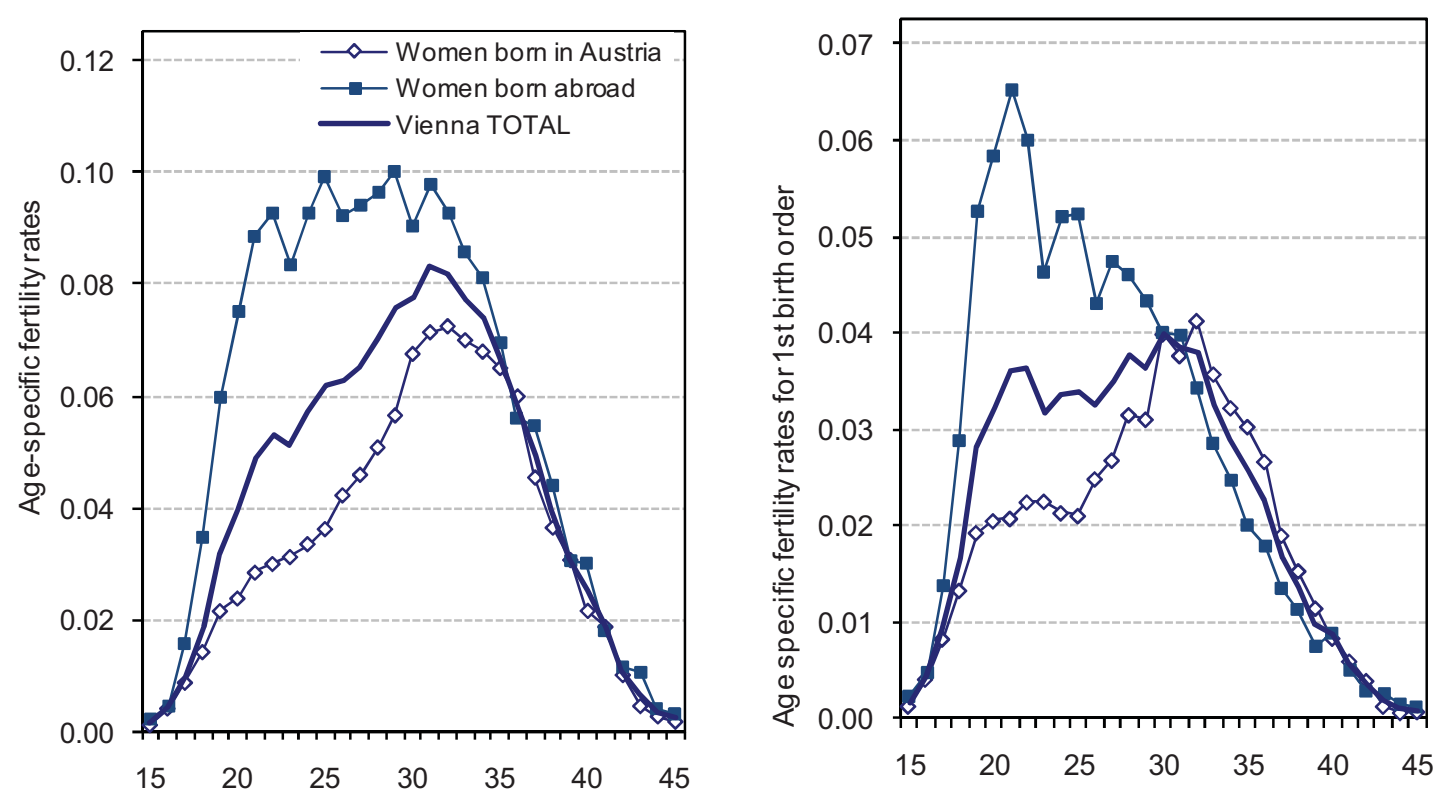

Source: Geburtenbarometer Vienna, authors' computations.

\section{Summary and Conclusions}

This study serves a double purpose. On the one hand, it introduces the new fertility monitoring system for the city of Vienna, modelled on an earlier example of the Geburtenbarometer for Austria and gives an overview of the data, methods and indicators used as well as of the main results. On the other, it provides a substantive evidence and discussion of fertility trends and patterns in Vienna and contrasts them with the data for other regions of Austria and for the whole country. Because fertility in Vienna differs markedly between the 'native' (Austrian-born) and foreign-born women, our analysis has paid attention to these fertility differentials and their influence on the overall fertility patterns for Vienna and Austria. To our knowledge, our report is the first one analysing period fertility rates in Austria by the mother's country of birth, although we were able to reconstruct them only for a short period since 2002 and we could distinguish only between the women born in Austria and those born abroad, without giving a finer analysis by country of origin. To date, studies on period fertility in Austria analysed data specified only by the mother's nationality (country of citizenship), which gives a distorted picture of immigrants' fertility levels and their contribution to Austrian fertility because many long-term migrants have received Austrian citizenship during the course of their stay in Austria.

Throughout much of the twentieth century, Vienna recorded fertility rates deep below those observed in other parts of Austria and the period Total Fertility Rate in Vienna fell to 'lowest-low' levels below 1.3 at least four times during the 20th century: in the first half of the 1930s, at the turn of the 1940s and 1950s, in the mid-1970s and briefly in 1997-99. Extreme low fertility in the past led to an early onset of rapid population ageing, high rates of natural population decline and shrinking population in the 1960s and 1970s (Lutz et al. 2003). Subsequently, population trends in Vienna turned around the corner and by 2005 Vienna had a growing population, increasing numbers of births, a minor rate of natural population 
increase that surpassed the natural population increase in all of Austria, and a fertility level converging to that for the whole country.

Our analysis of Viennese fertility yields important insights that are likely to be relevant to many other large cities in Europe. We show that the fertility rates in Vienna and Austria converged largely due to the massive decline in fertility rates in the whole of Austria between the mid-1960s and the mid-1980s combined with an initially slower decline and later a slight increase in fertility rates in the city of Vienna. This convergence is apparent in the time series of the period Total Fertility Rates and the Period Average Parity - two indicators regularly computed in the Geburtenbarometer - as well as in the tempo-adjusted TFR which aims to filter out the effects of changes in the timing of childbearing on period fertility and which recently stood above 1.6 in both Vienna and Austria alike.

Fertility trends in Vienna have been increasingly influenced by a growing population of immigrants who have, on average, higher fertility rates and who currently account for more than one-half of all births in Vienna. Migrant women in Vienna not only had a rapidly increasing share of the total births since the mid-1980s and thus contributed to a gradual increase in the absolute number of births in Vienna, but their higher fertility rates also helped to push period fertility towards the levels recorded in other regions of Austria and, in the case of the period TFR, to erase the gap between Austria and Vienna. The net impact of migrant women on the period TFR in Vienna in 2002-2009 amounted to 0.3 in absolute terms. In particular, migrant women have much higher third- and higher-order birth rates and appear to be the main driving force behind the rise in higher-order fertility rates in Vienna during the late 1990s and their subsequent convergence between Vienna and the whole of Austria. While Vienna retains lower first- and second-birth rates, its third- and fourth-parity progression rates have surpassed those for Austria since the early 2000s. Without migration, Vienna would remain a region with fertility rates deep below the rest of Austria and with continuously decreasing numbers of births. In addition, immigrant women in Vienna have a considerably younger childbearing schedule, contributing thus to the substantial variability in the age pattern of childbearing observed there.

In a broader perspective, Vienna can be seen as an example of a unique demographic development, a city with high childlessness and low fertility, but also with a positive balance between births and deaths and sustained population growth, where the population trends are strongly influenced by direct and (especially through fertility) indirect effects of migration. The case of Vienna holds two important conclusions for contemporary developed countries. First, sustained population growth can be achieved through intensive migration even in settings with a long history of very low fertility. Second, fertility rates, even when reaching extreme low levels for long periods of time, may bounce back to higher levels, either through an increase in fertility among native-born women, or through a gradual replacement of lowfertility populations by more fertile groups, which may come from other regions of the same country or from abroad. Such scenarios may hold for many prosperous regions that serve as magnets of immigration, including some rapidly urbanising developing countries whose cities have also reached very low fertility levels. 


\section{References}

Bongaarts, J. and G. Feeney. 1998. "On the quantum and tempo of fertility”. Population and Development Review 24 (2): 271-291.

Coleman, D. 1994. "Trends in fertility and intermarriage among immigrant populations in Western Europe as measures of integration." Journal of Biosocial Science 26: 107-136.

Cottrel, A. 2004. Gnu regression, econometrics and time-series library - Gretl. Accessed on [http://gretl.sourceforge.net].

Council of Europe. 1990. Cohort fertility in member states of the Council of Europe. Population Studies, No. 21, Strasbourg: Council of Europe.

Eurostat. 2009. Population and Social Conditions. Online database accessed on [http://epp.eurostat.ec.europa.eu].

Garssen, J. and H. Nicolaas. 2008. "Fertility of Turkish and Moroccan women in the Netherlands: Adjustment to native level within one generation." Demographic Research 19(33): 1249-1280.

Gisser, R. et al. 1975. Die persönliche Situation der Frau. Volume 4 in: Bericht über die Situation der Frau in Österreich. Vienna: Bundeskanzleramt.

Haug, W., P. Compton, and Y. Courbage (eds.). 2002. The Demographic Characteristics of Immigrant Populations. Population Studies, No. 38, Strasbourg: Council of Europe Publishing.

Jasilioniene, A., D.A. Jdanov, T. Sobotka, E.M. Andreev, K. Zeman, and V.M. Shkolnikov. 2010. Methods protocol for the Human Fertility Database (Version: 2 July 2010)." Accessible on [http://www.humanfertility.org/Docs/methods.pdf].

Kulu, H. 2006. "Fertility of internal migrants: comparison between Austria and Poland." Population, Space and Place 12(3): 147-170.

Kytir, J. and A. Wisbauer. 2009. "Demographische Strukturen und Trends 2008." Statistische Nachrichten 64 (10/2009): 869-884.

Lutz, W, S. Scherbov, and A. Hanika. 2003. “'Vienna: a city beyond aging' - revisited and revised" Vienna Yearbook of Population Research 2003: 181-195.

Prskawetz, A., T. Sobotka, I. Buber, R. Gisser, and H. Engelhardt. 2008. “Austria: persistent low fertility since the mid-1980s." Demographic Research 19(12): 293-360.

Rallu, L. and L. Toulemon. 1994. "Period fertility measures. The construction of different indices and their application to France, 1946-89". Population, An English Selection 6: 59-94.

Sobotka, T. 2008. "The rising importance of migrants for childbearing in Europe." Demographic Research, Special Collection 7, Vol. 19, Article 9: 225-248.

Sobotka, T., M. Winkler-Dworak, M. R. Testa, W. Lutz, D. Philipov, H. Engelhardt and R. Gisser. 2005. "Monthly Estimates of the Quantum of Fertility: Towards a Fertility Monitoring System in Austria". Vienna Yearbook of Population Research 2005: 109-141.

Sobotka, T. and W. Lutz. 2009. "Misleading policy messages from the period TFR: Should we stop using it?" European Demographic Research Papers 4. Vienna: Vienna Institute of Demography. 
Spielauer, M. 2005. "Concentration of reproduction in Austria: General trends and differentials by educational attainment and urban-rural setting." Vienna Yearbook of Population Research 2005: 171-195.

Statistics Austria. 2005. Volkszählung 2001. Haushalte und Familien. Vienna: Statistics Austria.

Statistics Austria. 2009a. Demographisches Jahrbuch Österreichs 2008. Vienna: Statistics Austria.

Statistics Austria. 2009b. Demographische Indikatoren für Wien 1961-2008. Vienna: Statistics Austria.

Statistics Austria. 2010. Demographisches Jahrbuch Österreichs 2009. Vienna: Statistics Austria.

VID. 2010. Geburtenbarometer : Monthly Monitoring of Fertility in Austria. [http://www.oeaw.ac.at/vid/barometer/index.html]. 


\section{Appendix - Data, Figures, Tables}

Table A1 Summary indicators of period fertility in Austria, Vienna, and in other federal provinces of Austria combined, 1984-2009

\begin{tabular}{|c|c|c|c|c|c|c|c|c|c|c|c|c|}
\hline & \multicolumn{3}{|c|}{ Total Fertility Rate } & \multicolumn{3}{|c|}{ Mean age of at first birth } & \multicolumn{3}{|c|}{ PATFR1 } & \multicolumn{3}{|c|}{ PAP } \\
\hline & Vienna & Austria & $\begin{array}{c}\text { Other } \\
\text { regions }\end{array}$ & Vienna & Austria & $\begin{array}{c}\text { Other } \\
\text { regions }\end{array}$ & Vienna & Austria & $\begin{array}{l}\text { Other } \\
\text { regions }\end{array}$ & Vienna & Austria & $\begin{array}{l}\text { Other } \\
\text { regions }\end{array}$ \\
\hline 1984 & 1.35 & 1.52 & 1.56 & 25.0 & 24.1 & 23.9 & & & & & & \\
\hline 1985 & 1.33 & 1.47 & 1.51 & 25.2 & 24.3 & 24.1 & & & & & & \\
\hline 1986 & 1.32 & 1.45 & 1.48 & 25.2 & 24.4 & 24.2 & & & & & & \\
\hline 1987 & 1.33 & 1.43 & 1.45 & 25.4 & 24.6 & 24.4 & & & & & & \\
\hline 1988 & 1.38 & 1.45 & 1.46 & 25.4 & 24.7 & 24.5 & & & & & & \\
\hline 1989 & 1.38 & 1.45 & 1.46 & 25.4 & 24.8 & 24.6 & & & & & & \\
\hline 1990 & 1.39 & 1.46 & 1.48 & 25.5 & 24.9 & 24.8 & & & & & & \\
\hline 1991 & 1.43 & 1.51 & 1.53 & 25.3 & 24.9 & 24.8 & 0.75 & 0.78 & 0.79 & & & \\
\hline 1992 & 1.42 & 1.50 & 1.53 & 25.4 & 25.0 & 24.9 & 0.75 & 0.77 & 0.78 & & & \\
\hline 1993 & 1.40 & 1.50 & 1.53 & 25.4 & 25.1 & 25.0 & 0.74 & 0.76 & 0.77 & & & \\
\hline 1994 & 1.38 & 1.47 & 1.49 & 25.8 & 25.4 & 25.3 & 0.73 & 0.75 & 0.76 & & & \\
\hline 1995 & 1.33 & 1.42 & 1.45 & 26.0 & 25.6 & 25.5 & 0.73 & 0.75 & 0.75 & & & \\
\hline 1996 & 1.34 & 1.45 & 1.47 & 26.2 & 25.9 & 25.8 & 0.73 & 0.75 & 0.76 & & & \\
\hline 1997 & 1.29 & 1.39 & 1.42 & 26.4 & 26.0 & 25.9 & 0.72 & 0.74 & 0.75 & & & \\
\hline 1998 & 1.29 & 1.37 & 1.39 & 26.4 & 26.1 & 26.1 & 0.72 & 0.74 & 0.74 & & & \\
\hline 1999 & 1.29 & 1.34 & 1.36 & 26.6 & 26.3 & 26.2 & 0.73 & 0.73 & 0.73 & 1.40 & 1.50 & 1.52 \\
\hline 2000 & 1.34 & 1.36 & 1.37 & 26.5 & 26.4 & 26.3 & 0.74 & 0.73 & 0.73 & 1.45 & 1.51 & 1.53 \\
\hline 2001 & 1.31 & 1.33 & 1.34 & 26.6 & 26.5 & 26.5 & 0.73 & 0.73 & 0.73 & 1.43 & 1.48 & 1.50 \\
\hline 2002 & 1.41 & 1.39 & 1.39 & 26.9 & 26.7 & 26.7 & 0.71 & 0.75 & 0.76 & 1.49 & 1.57 & 1.61 \\
\hline 2003 & 1.39 & 1.38 & 1.38 & 27.0 & 26.9 & 26.9 & 0.71 & 0.74 & 0.76 & 1.50 & 1.56 & 1.59 \\
\hline 2004 & 1.41 & 1.42 & 1.43 & 27.0 & 27.0 & 27.0 & 0.72 & 0.75 & 0.76 & 1.52 & 1.59 & 1.63 \\
\hline 2005 & 1.37 & 1.41 & 1.42 & 27.3 & 27.2 & 27.2 & 0.71 & 0.75 & 0.76 & 1.49 & 1.58 & 1.62 \\
\hline 2006 & 1.39 & 1.40 & 1.41 & 27.7 & 27.5 & 27.4 & 0.72 & 0.75 & 0.76 & 1.52 & 1.58 & 1.60 \\
\hline 2007 & 1.36 & 1.38 & 1.39 & 27.8 & 27.6 & 27.6 & 0.71 & 0.74 & 0.75 & 1.49 & 1.54 & 1.57 \\
\hline 2008 & 1.39 & 1.41 & 1.42 & 28.0 & 27.7 & 27.7 & 0.73 & 0.75 & 0.75 & 1.52 & 1.57 & 1.59 \\
\hline 2009 & 1.36 & 1.39 & 1.41 & 28.0 & 27.9 & 27.9 & 0.73 & 0.74 & 0.75 & 1.49 & 1.54 & 1.57 \\
\hline
\end{tabular}

Table A2 Period total fertility rate and mean age at childbearing by birth order in Vienna, 1984-2009

\begin{tabular}{|c|c|c|c|c|c|c|c|c|c|c|c|c|}
\hline & \multicolumn{6}{|c|}{ Total fertility rate by birth order } & \multicolumn{6}{|c|}{ Mean age of mothers by birth order } \\
\hline & 1 & 2 & 3 & 4 & $5+$ & TOTAL & 1 & 2 & 3 & 4 & $5+$ & TOTAL \\
\hline 1984 & 0.71 & 0.44 & 0.14 & 0.04 & 0.02 & 1.35 & 25.0 & 27.4 & 29.7 & 31.3 & 34.2 & 26.6 \\
\hline 1985 & 0.70 & 0.42 & 0.14 & 0.04 & 0.02 & 1.33 & 25.2 & 27.7 & 30.2 & 31.3 & 33.6 & 26.9 \\
\hline 1986 & 0.71 & 0.41 & 0.13 & 0.05 & 0.02 & 1.32 & 25.2 & 27.8 & 29.9 & 31.5 & 33.8 & 26.9 \\
\hline 1987 & 0.71 & 0.42 & 0.13 & 0.04 & 0.02 & 1.33 & 25.4 & 27.8 & 30.1 & 32.0 & 34.4 & 27.0 \\
\hline 1988 & 0.74 & 0.43 & 0.14 & 0.04 & 0.02 & 1.38 & 25.4 & 27.9 & 30.5 & 31.6 & 33.5 & 27.0 \\
\hline 1989 & 0.73 & 0.44 & 0.14 & 0.04 & 0.03 & 1.38 & 25.4 & 28.0 & 30.5 & 31.8 & 34.0 & 27.1 \\
\hline 1990 & 0.73 & 0.45 & 0.14 & 0.04 & 0.02 & 1.39 & 25.5 & 28.2 & 30.7 & 32.1 & 34.3 & 27.3 \\
\hline 1991 & 0.76 & 0.45 & 0.14 & 0.05 & 0.02 & 1.43 & 25.3 & 28.0 & 30.5 & 31.6 & 34.4 & 27.0 \\
\hline 1992 & 0.75 & 0.45 & 0.15 & 0.04 & 0.02 & 1.42 & 25.4 & 28.0 & 30.4 & 32.3 & 34.1 & 27.1 \\
\hline 1993 & 0.73 & 0.46 & 0.15 & 0.05 & 0.02 & 1.40 & 25.4 & 28.0 & 30.5 & 31.9 & 34.0 & 27.1 \\
\hline 1994 & 0.71 & 0.46 & 0.14 & 0.05 & 0.02 & 1.38 & 25.8 & 28.2 & 30.4 & 32.1 & 34.3 & 27.4 \\
\hline 1995 & 0.70 & 0.43 & 0.14 & 0.04 & 0.02 & 1.33 & 26.0 & 28.3 & 30.3 & 32.1 & 34.3 & 27.5 \\
\hline 1996 & 0.70 & 0.44 & 0.14 & 0.04 & 0.02 & 1.34 & 26.2 & 28.5 & 30.5 & 32.3 & 34.1 & 27.7 \\
\hline 1997 & 0.67 & 0.42 & 0.14 & 0.04 & 0.02 & 1.29 & 26.4 & 28.7 & 30.8 & 33.1 & 34.6 & 27.9 \\
\hline 1998 & 0.67 & 0.42 & 0.14 & 0.04 & 0.02 & 1.29 & 26.4 & 28.8 & 30.6 & 32.3 & 34.7 & 27.9 \\
\hline 1999 & 0.68 & 0.42 & 0.14 & 0.04 & 0.02 & 1.29 & 26.6 & 29.0 & 30.7 & 32.4 & 34.7 & 28.1 \\
\hline 2000 & 0.70 & 0.44 & 0.14 & 0.05 & 0.02 & 1.34 & 26.5 & 29.0 & 30.9 & 32.3 & 34.5 & 28.1 \\
\hline 2001 & 0.68 & 0.41 & 0.15 & 0.05 & 0.02 & 1.31 & 26.6 & 29.1 & 31.0 & 32.0 & 34.5 & 28.2 \\
\hline 2002 & 0.70 & 0.47 & 0.17 & 0.05 & 0.02 & 1.41 & 26.9 & 29.1 & 31.0 & 32.3 & 34.2 & 28.4 \\
\hline 2003 & 0.69 & 0.45 & 0.17 & 0.06 & 0.03 & 1.39 & 27.0 & 29.3 & 31.3 & 32.7 & 34.1 & 28.6 \\
\hline 2004 & 0.71 & 0.44 & 0.17 & 0.06 & 0.03 & 1.41 & 27.0 & 29.5 & 31.2 & 32.5 & 34.6 & 28.7 \\
\hline 2005 & 0.70 & 0.43 & 0.17 & 0.05 & 0.03 & 1.37 & 27.3 & 29.7 & 31.3 & 32.8 & 34.9 & 28.9 \\
\hline 2006 & 0.70 & 0.44 & 0.17 & 0.06 & 0.03 & 1.39 & 27.7 & 29.9 & 31.4 & 32.8 & 35.0 & 29.2 \\
\hline 2007 & 0.68 & 0.44 & 0.16 & 0.06 & 0.03 & 1.36 & 27.8 & 30.0 & 31.7 & 33.0 & 34.7 & 29.4 \\
\hline 2008 & 0.70 & 0.44 & 0.16 & 0.06 & 0.03 & 1.39 & 28.0 & 30.3 & 31.9 & 33.2 & 35.0 & 29.5 \\
\hline 2009 & 0.69 & 0.42 & 0.16 & 0.06 & 0.03 & 1.36 & 28.0 & 30.6 & 31.9 & 33.3 & 34.9 & 29.6 \\
\hline
\end{tabular}


Table A3: Parity progression ratios and Period Average Parity (PAP) in Vienna, 1999-2009

\begin{tabular}{|l|cccc|cccccc|c|}
\hline & \multicolumn{6}{|c|}{ Parity Progression Ratios (PPR) } & \multicolumn{6}{c|}{ Period Average Parity (PAP) by birth order } \\
\hline & 0->1 & $\mathbf{1 - > 2}$ & $\mathbf{2 - > 3}$ & $\mathbf{3 - > 4}$ & $\mathbf{1}$ & $\mathbf{2}$ & $\mathbf{3}$ & $\mathbf{4}$ & $\mathbf{5 +}$ & TOTAL \\
\hline $\mathbf{1 9 9 9}$ & 0.73 & 0.62 & 0.33 & 0.29 & 0.73 & 0.46 & 0.15 & 0.04 & 0.02 & $\mathbf{1 . 4 0}$ \\
$\mathbf{2 0 0 0}$ & 0.74 & 0.64 & 0.33 & 0.35 & 0.74 & 0.47 & 0.16 & 0.06 & 0.03 & $\mathbf{1 . 4 5}$ \\
$\mathbf{2 0 0 1}$ & 0.73 & 0.62 & 0.36 & 0.35 & 0.73 & 0.45 & 0.16 & 0.06 & 0.03 & $\mathbf{1 . 4 3}$ \\
$\mathbf{2 0 0 2}$ & 0.71 & 0.67 & 0.39 & 0.38 & 0.71 & 0.48 & 0.19 & 0.07 & 0.04 & $\mathbf{1 . 4 9}$ \\
$\mathbf{2 0 0 3}$ & 0.71 & 0.67 & 0.41 & 0.39 & 0.71 & 0.47 & 0.19 & 0.08 & 0.05 & $\mathbf{1 . 5 0}$ \\
$\mathbf{2 0 0 4}$ & 0.72 & 0.67 & 0.40 & 0.39 & 0.72 & 0.48 & 0.20 & 0.08 & 0.05 & $\mathbf{1 . 5 2}$ \\
$\mathbf{2 0 0 5}$ & 0.71 & 0.66 & 0.41 & 0.37 & 0.71 & 0.47 & 0.19 & 0.07 & 0.04 & $\mathbf{1 . 4 9}$ \\
$\mathbf{2 0 0 6}$ & 0.72 & 0.67 & 0.41 & 0.39 & 0.72 & 0.48 & 0.20 & 0.08 & 0.04 & $\mathbf{1 . 5 2}$ \\
$\mathbf{2 0 0 7}$ & 0.71 & 0.66 & 0.40 & 0.36 & 0.71 & 0.47 & 0.19 & 0.07 & 0.04 & $\mathbf{1 . 4 9}$ \\
$\mathbf{2 0 0 8}$ & 0.73 & 0.67 & 0.40 & 0.36 & 0.73 & 0.49 & 0.19 & 0.07 & 0.04 & $\mathbf{1 . 5 2}$ \\
$\mathbf{2 0 0 9}$ & 0.73 & 0.65 & 0.39 & 0.36 & 0.73 & 0.47 & 0.18 & 0.07 & 0.04 & $\mathbf{1 . 4 9}$ \\
\hline
\end{tabular}

Table A4: Quarterly indicators of period fertility and parity progression ratios in Vienna, 2002-2010

\begin{tabular}{|c|c|c|c|c|c|c|c|}
\hline Year & Quarter & TFR & PAP & $\begin{array}{c}\text { PPR 0- } \\
>1\end{array}$ & $\begin{array}{c}\text { PPR 1- } \\
>2\end{array}$ & $\begin{array}{c}\text { PPR 2- } \\
>3\end{array}$ & $\begin{array}{c}\text { PPR 3- } \\
>4\end{array}$ \\
\hline \multirow{4}{*}{2002} & I & 1.37 & 1.47 & 0.71 & 0.66 & 0.39 & 0.40 \\
\hline & II & 1.40 & 1.51 & 0.71 & 0.68 & 0.40 & 0.41 \\
\hline & III & 1.41 & 1.55 & 0.72 & 0.70 & 0.39 & 0.40 \\
\hline & IV & 1.41 & 1.55 & 0.72 & 0.70 & 0.41 & 0.35 \\
\hline \multirow[t]{4}{*}{2003} & I & 1.40 & 1.54 & 0.72 & 0.69 & 0.41 & 0.37 \\
\hline & II & 1.39 & 1.54 & 0.71 & 0.69 & 0.41 & 0.41 \\
\hline & III & 1.39 & 1.54 & 0.72 & 0.69 & 0.40 & 0.40 \\
\hline & IV & 1.39 & 1.52 & 0.72 & 0.69 & 0.40 & 0.38 \\
\hline \multirow[t]{4}{*}{2004} & I & 1.38 & 1.52 & 0.71 & 0.69 & 0.39 & 0.41 \\
\hline & II & 1.40 & 1.55 & 0.73 & 0.69 & 0.40 & 0.41 \\
\hline & III & 1.42 & 1.59 & 0.73 & 0.69 & 0.43 & 0.39 \\
\hline & IV & 1.44 & 1.61 & 0.73 & 0.70 & 0.43 & 0.39 \\
\hline \multirow[t]{4}{*}{2005} & I & 1.42 & 1.58 & 0.72 & 0.70 & 0.43 & 0.41 \\
\hline & II & 1.39 & 1.55 & 0.72 & 0.69 & 0.41 & 0.38 \\
\hline & III & 1.36 & 1.51 & 0.72 & 0.68 & 0.40 & 0.35 \\
\hline & IV & 1.34 & 1.51 & 0.73 & 0.66 & 0.41 & 0.36 \\
\hline \multirow[t]{4}{*}{2006} & I & 1.36 & 1.54 & 0.72 & 0.67 & 0.40 & 0.42 \\
\hline & II & 1.40 & 1.55 & 0.72 & 0.69 & 0.41 & 0.38 \\
\hline & III & 1.40 & 1.57 & 0.73 & 0.69 & 0.40 & 0.40 \\
\hline & IV & 1.39 & 1.58 & 0.73 & 0.69 & 0.44 & 0.38 \\
\hline \multirow[t]{4}{*}{2007} & I & 1.38 & 1.54 & 0.72 & 0.68 & 0.42 & 0.37 \\
\hline & II & 1.37 & 1.52 & 0.71 & 0.69 & 0.40 & 0.37 \\
\hline & III & 1.37 & 1.54 & 0.73 & 0.69 & 0.40 & 0.36 \\
\hline & IV & 1.37 & 1.55 & 0.73 & 0.68 & 0.39 & 0.38 \\
\hline \multirow[t]{4}{*}{2008} & I & 1.38 & 1.54 & 0.73 & 0.69 & 0.39 & 0.38 \\
\hline & II & 1.39 & 1.55 & 0.74 & 0.69 & 0.40 & 0.35 \\
\hline & III & 1.39 & 1.57 & 0.74 & 0.69 & 0.40 & 0.35 \\
\hline & IV & 1.37 & 1.57 & 0.74 & 0.69 & 0.41 & 0.36 \\
\hline \multirow[t]{4}{*}{2009} & I & 1.36 & 1.52 & 0.73 & 0.67 & 0.39 & 0.38 \\
\hline & II & 1.36 & 1.52 & 0.73 & 0.66 & 0.40 & 0.38 \\
\hline & III & 1.37 & 1.54 & 0.74 & 0.67 & 0.41 & 0.36 \\
\hline & IV & 1.38 & 1.56 & 0.74 & 0.68 & 0.40 & 0.36 \\
\hline \multirow[t]{3}{*}{2010} & I & 1.42 & 1.53 & 0.72 & 0.68 & 0.41 & 0.33 \\
\hline & II & 1.42 & 1.54 & 0.73 & 0.69 & 0.40 & 0.35 \\
\hline & III & 1.42 & 1.56 & 0.73 & 0.71 & 0.40 & 0.35 \\
\hline
\end{tabular}


Table A5: Period total fertility rate, and the mean age of mother at childbearing $(M A B)$ and at first birth (MAB1) by country of birth of the mother, 2002-2009

\begin{tabular}{|c|c|c|c|c|c|c|c|c|c|}
\hline & \multicolumn{3}{|c|}{ Vienna } & \multicolumn{3}{|c|}{ Austria } & \multicolumn{3}{|c|}{ Other regions of Austria } \\
\hline & \multicolumn{3}{|c|}{$\begin{array}{r}\text { Country of birth } \\
\text { TOTA }\end{array}$} & \multicolumn{3}{|c|}{$\begin{array}{r}\text { Country of birth } \\
\text { TOTA }\end{array}$} & \multicolumn{3}{|c|}{ Country of birth } \\
\hline & Austria & other & $\mathbf{L}$ & Austria & other & $\mathbf{L}$ & Austria & other & $\mathbf{L}$ \\
\hline \multicolumn{10}{|l|}{ TFR } \\
\hline 2002 & 1.12 & 2.05 & 1.41 & 1.29 & 1.99 & 1.39 & 1.32 & 1.95 & 1.39 \\
\hline 2003 & 1.10 & 1.99 & 1.39 & 1.27 & 1.92 & 1.38 & 1.31 & 1.88 & 1.38 \\
\hline 2004 & 1.10 & 1.99 & 1.41 & 1.30 & 1.98 & 1.42 & 1.35 & 1.98 & 1.43 \\
\hline 2005 & 1.09 & 1.87 & 1.37 & 1.29 & 1.94 & 1.41 & 1.33 & 1.99 & 1.42 \\
\hline 2006 & 1.11 & 1.87 & 1.39 & 1.29 & 1.93 & 1.40 & 1.33 & 1.99 & 1.41 \\
\hline 2007 & 1.09 & 1.82 & 1.36 & 1.25 & 1.92 & 1.38 & 1.29 & 2.00 & 1.39 \\
\hline 2008 & 1.11 & 1.83 & 1.39 & 1.29 & 1.90 & 1.41 & 1.33 & 1.96 & 1.42 \\
\hline 2009 & 1.08 & 1.82 & 1.36 & 1.28 & 1.85 & 1.39 & 1.32 & 1.89 & 1.41 \\
\hline \multicolumn{10}{|l|}{ MAB } \\
\hline 2002 & 28.8 & 27.8 & 28.4 & 28.7 & 27.8 & 28.6 & 28.7 & 27.7 & 28.6 \\
\hline 2003 & 29.1 & 27.9 & 28.6 & 28.9 & 28.0 & 28.8 & 28.9 & 28.0 & 28.8 \\
\hline 2004 & 29.3 & 27.8 & 28.7 & 29.0 & 27.9 & 28.8 & 29.0 & 28.0 & 28.8 \\
\hline 2005 & 29.5 & 28.2 & 28.9 & 29.3 & 28.1 & 29.0 & 29.2 & 28.0 & 29.0 \\
\hline 2006 & 29.8 & 28.3 & 29.2 & 29.5 & 28.2 & 29.2 & 29.4 & 28.1 & 29.2 \\
\hline 2007 & 30.1 & 28.4 & 29.4 & 29.7 & 28.3 & 29.4 & 29.6 & 28.2 & 29.3 \\
\hline 2008 & 30.3 & 28.5 & 29.5 & 29.8 & 28.4 & 29.5 & 29.7 & 28.2 & 29.5 \\
\hline 2009 & 30.5 & 28.5 & 29.6 & 30.0 & 28.4 & 29.7 & 29.9 & 28.3 & 29.7 \\
\hline \multicolumn{10}{|c|}{ MAB1 } \\
\hline 2002 & 27.5 & 25.5 & 26.9 & 27.0 & 25.3 & 26.7 & 26.9 & 25.1 & 26.7 \\
\hline 2003 & 27.8 & 25.6 & 27.0 & 27.2 & 25.4 & 26.9 & 27.1 & 25.3 & 26.9 \\
\hline 2004 & 28.0 & 25.7 & 27.0 & 27.4 & 25.5 & 27.0 & 27.3 & 25.4 & 27.0 \\
\hline 2005 & 28.3 & 25.9 & 27.3 & 27.7 & 25.7 & 27.2 & 27.5 & 25.5 & 27.2 \\
\hline 2006 & 28.8 & 26.1 & 27.7 & 27.9 & 25.9 & 27.5 & 27.7 & 25.7 & 27.4 \\
\hline 2007 & 28.9 & 26.3 & 27.8 & 28.1 & 26.1 & 27.6 & 27.9 & 26.0 & 27.6 \\
\hline 2008 & 29.2 & 26.5 & 28.0 & 28.2 & 26.2 & 27.7 & 28.0 & 26.0 & 27.7 \\
\hline 2009 & 29.1 & 26.4 & 27.9 & 28.4 & 26.3 & 27.9 & 28.3 & 26.2 & 27.9 \\
\hline
\end{tabular}

Tables A6a and 6b: Proportion of live births by country of birth of the mother, Austria and Vienna, 2009 (top ten countries)

\begin{tabular}{|l|r|}
\hline Country of birth & Austria \\
\hline Austria & $70.7 \%$ \\
\hline Turkey & $5.6 \%$ \\
Bosnia and Herzegovina & $3.2 \%$ \\
Germany & $2.9 \%$ \\
Serbia & $2.1 \%$ \\
Romania & $1.6 \%$ \\
Russia & $1.3 \%$ \\
Kosovo & $1.3 \%$ \\
Poland & $1.1 \%$ \\
Slovakia & $0.7 \%$ \\
\hline other & $9.5 \%$ \\
\hline
\end{tabular}

\begin{tabular}{|l|r|}
\hline Country of birth & Vienna \\
\hline Austria & $46.2 \%$ \\
\hline Turkey & $10.4 \%$ \\
Serbia & $6.1 \%$ \\
Bosnia and Herzegovina & $3.8 \%$ \\
Poland & $3.4 \%$ \\
Germany & $3.0 \%$ \\
Romania & $2.4 \%$ \\
Russia & $1.9 \%$ \\
Slovakia & $1.7 \%$ \\
Kosovo & $1.6 \%$ \\
\hline other & $19.7 \%$ \\
\hline
\end{tabular}


Table A7a: Distribution of live births by birth order among mothers born in Austria and mothers born abroad, 2009

\begin{tabular}{|c|c|c|c|c|c|c|}
\hline \multirow{3}{*}{$\begin{array}{l}\text { Birth } \\
\text { order }\end{array}$} & \multicolumn{3}{|c|}{ Vienna } & \multicolumn{3}{|c|}{ Austria } \\
\hline & \multicolumn{3}{|c|}{ Country of birth } & \multicolumn{3}{|c|}{ Country of birth } \\
\hline & Austria & other & Total & Austria & other & Total \\
\hline 1 & $55 \%$ & $45 \%$ & $50 \%$ & $49 \%$ & $43 \%$ & $47 \%$ \\
\hline 2 & $31 \%$ & $32 \%$ & $31 \%$ & $36 \%$ & $33 \%$ & $35 \%$ \\
\hline 3 & $9 \%$ & $15 \%$ & $12 \%$ & $12 \%$ & $15 \%$ & $13 \%$ \\
\hline 4 & $3 \%$ & $6 \%$ & $4 \%$ & $3 \%$ & $6 \%$ & $4 \%$ \\
\hline $5+$ & $2 \%$ & $3 \%$ & $2 \%$ & $1 \%$ & $3 \%$ & $2 \%$ \\
\hline Total & $100 \%$ & $100 \%$ & $100 \%$ & $100 \%$ & $100 \%$ & $100 \%$ \\
\hline
\end{tabular}

Table A7b: Share of live births in Vienna and in Austria to mothers born in Austria and mothers born abroad, by birth order, 2009

\begin{tabular}{|l|rrr|rrr|}
\hline \multirow{2}{*}{} & \multicolumn{3}{|c|}{ Vienna } & \multicolumn{3}{c|}{ Austria } \\
\hline \multirow{3}{*}{ Birth } & \multicolumn{3}{|c|}{ Country of birth } & \multicolumn{3}{c|}{ Country of birth } \\
\cline { 2 - 7 } order & Austria & other & Total & Austria & other & Total \\
\hline $\mathbf{1}$ & $51 \%$ & $49 \%$ & $\mathbf{1 0 0} \%$ & $73 \%$ & $27 \%$ & $\mathbf{1 0 0} \%$ \\
$\mathbf{2}$ & $46 \%$ & $54 \%$ & $\mathbf{1 0 0} \%$ & $73 \%$ & $27 \%$ & $\mathbf{1 0 0} \%$ \\
$\mathbf{3}$ & $35 \%$ & $65 \%$ & $\mathbf{1 0 0} \%$ & $65 \%$ & $35 \%$ & $\mathbf{1 0 0} \%$ \\
$\mathbf{4}$ & $30 \%$ & $70 \%$ & $\mathbf{1 0 0} \%$ & $56 \%$ & $44 \%$ & $\mathbf{1 0 0} \%$ \\
$\mathbf{5}+$ & $30 \%$ & $70 \%$ & $\mathbf{1 0 0} \%$ & $48 \%$ & $52 \%$ & $\mathbf{1 0 0} \%$ \\
\hline Total & $46 \%$ & $54 \%$ & $\mathbf{1 0 0} \%$ & $71 \%$ & $29 \%$ & $\mathbf{1 0 0} \%$ \\
\hline
\end{tabular}




\section{VIENNA INSTITUTE OF DEMOGRAPHY}

\section{Working Papers}

Feichtinger Gustav, Michael Kuhn, Alexia Prskawetz, and Stefan Wrzaczek, The Reproductive Value as Part of the Shadow Price of Population, VID Working Paper 06/2011.

Barakat, Bilal, Time is Money: Could Deferred Graduate Retirement Finance Higher Education?, VID Working Paper 05/2011.

Riosmena, Fernando, Maria Winkler-Dworak, Alexia Prskawetz, and Gustav Feichtinger, The Impact of Policies Influencing the Demography of Age Structured

Populations: Lessons from Academies of Science, VID Working Paper 04/2011.

Buber, Isabella and Katrin Fliegenschnee, Are you Ready for a Child? A Methodological Triangulation on Fertility Intentions in Austria, VID Working Paper $03 / 2011$.

Fent, Thomas, Belinda Aparicio Diaz, and Alexia Prskawetz, Family Policies in the Context of Low Fertility and Social Structure, VID Working Paper 02/2011.

Buber, Isabella, Caroline Berghammer, and Alexia Prskawetz, Doing Science, Forgoing Childbearing? Evidence from a Sample of Female Scientists in Austria, VID Working Paper 01/2011.

Strulik, Holger, Klaus Prettner, and Alexia Prskawetz, R\&D-Based Growth in the Post-Modern Era, VID Working Paper 09/2010.

Prettner, Klaus and Alexia Prskawetz, Demographic Change in Models of Endogenous Economic Growth. A Survey, VID Working Paper 08/2010.

Flandorfer, Priska, Christian Wegner, and Isabella Buber, Gender Roles and Smoking Behaviour, VID Working Paper 07/2010.

Barakat, Bilal, Johannes Holler, Klaus Prettner, and Julia Schuster, The Impact of the Economic Crisis on Labour and Education in Europe, VID Working Paper 06/2010.

Grafeneder-Weissteiner, Theresa and Klaus Prettner, Agglomeration Processes in Ageing Societies, VID Working Paper 05/2010.

Buber, Isabella, Parity-specific weights for the Austrian Generations and Gender Survey, VID Working Paper 04/2010.

The Vienna Institute of Demography Working Paper Series receives only limited review. Views or opinions expressed herein are entirely those of the authors. 